\title{
The redistributive effects of the EU budget: an analysis and a proposal for reform
}

\author{
Angel de la Fuente \\ Instituto de Análisis Económico (CSIC) \\ and \\ Rafael Doménech* \\ Universidad de Valencia
}

February 2000

\begin{abstract}
This paper analyzes the redistributive effects of the EU budget during the period 1986-98, explores the implications of the Berlin budget agreement and advances a proposal for setting member countries' budgetary balances in a manner consistent with a simple equity criterion based on relative income per capita. Using an extension of a standard methodology, we find that the redistributive impact of the EU budget has been considerable in view of its small size, that it has tended to increase over time, and that it is mostly due to the effects of structural programmes. We also find that, in spite of the relative loss of weight of structural transfers, the expenditure side of the Berlin budget agreement represents a noticeable (but small) improvement over the previous financial perspectives in terms of both its redistributive impact and its horizontal equity properties. Our proposed allocation criterion involves the correction of horizontal inequities while preserving the current degree of redistribution. This would involve a sizable reallocation of net contributions across rich countries and only a modest reduction in north-south fiscal flows.
\end{abstract}

Keywords: European Union, fiscal flows

JEL Classification: H11, H77, H87

* This paper was written as part of a research project cofinanced by the European Fund for Regional Development and Fundación Caixa Galicia. Additional financial support was provided by the Spanish Ministry of Education and Culture under grants SEC99-1189 and SEC99-0820. We are grateful to Juan Varela, Antonio Maudes, Alberto Cerdá and Andries Brandsma for their helpful comments.

Correspondence to: Angel de la Fuente, Instituto de Análisis Económico, Campus de la Universidad Autónoma de Barcelona, 08193, Bellaterra, Barcelona, Spain. Tel: 93-580-6612. Fax: 93-580-1452. E-Mail address: delafuente@cc.uab.es, or

Rafael Domenech, Departamento de Análisis Económico, Universidad de Valencia, Campus de los Naranjos, 46022 Valencia, Spain; E-Mail address: rafael.domenech@uv.es 


\section{1.- Introduction}

This paper analyzes the redistributive effects of the EU budget during the period 1986-98, explores the likely implications of the Berlin budget agreement and advances a proposal for setting member countries' fiscal balances in a manner consistent with a simple equity criterion. In the positive part of the paper, we extend a standard methodology for the analysis of the impact of fiscal flows that involves running regressions of appropriately normalized budget items on relative incomes per capita. The estimated coefficients and the residuals of these regressions are then used to construct annual indicators of the degree of redistribution induced by the overall EU budget and by each of its expenditure and revenue items, as well as measures of total and partial national budgetary balances corrected for income per capita. The results provide a compact and fairly complete characterization of the redistributive impact of fiscal flows across Union members over the last decade. Our indicators, moreover, have some convenient additivity properties and are easier to interpret and to work with than the Lorenz curves often used to describe the redistributive effects of Union programmes.

The regressions we estimate can also be seen as an attempt to extract from the data a simple allocation rule for budget resources that is consistent with the principle of cohesion and presumably reflects the consensus on the desirable degree of redistribution implicit in the status quo. In the second part of the paper, we argue that the explicit adoption of such a rule (relating national budget balances to relative incomes per capita) would be useful in focusing and simplifying EU budget negotiations, in increasing their transparency, and in improving horizontal equity across member states. In addition, our proposal would change the incentives faced by national governments in a way that should improve the efficiency of EU expenditure programmes. Using as a reference the 1998 situation, we explore the implications of the proposed rule and conclude that there is plenty of room for redistributing resources across member states in a way that will mitigate perceived inequities without reducing the overall degree of redistribution. We also find that the recent Berlin budget agreement is a partial step in the right direction, as it can be expected to increase slightly the degree of redistribution of the EU budget while reducing somewhat the existing fiscal disparities across countries with similar income levels. 


\section{2.- Measuring the redistributive impact of the EU budget}

This section describes the methodology used to analyze the effects of fiscal flows across EU states. As a number of authors have done in the related literature, ${ }^{1}$ we estimate a series of regressions of various budget items on relative "gross" income per capita (GNP per capita before EU transfers and contributions) in order to obtain a redistribution coefficient that measures the fraction of the income differential with the EU average that is eliminated by the relevant fiscal flow. The residual for a given country in this regression will measure the deviation from the implicit allocation rule described by the fitted regression line, and will accordingly be interpreted as an indicator of the adjusted "fiscal treatment" of the country under the relevant programme. It should be noted from the outset that we regard these regressions as simply a convenient way to summarize the data, and not as a way to test hypotheses. Hence, we will work only with point estimates and disregard any discussion of statistical significance or intervals of confidence. We will, however, be concerned with the dispersion of the residuals as an inverse indicator of the degree of horizontal fairness of the allocation, given the average degree of redistribution implicit in the estimated equation.

Our starting point will be a decomposition of each country's per capita net budget balance with the Union $(n b)$ as the algebraic sum of a series of per capita transfers and contributions:

$$
\text { (1) } n b_{i}=\text { t.tot }_{i}-\text { c.tot }_{i}=\left(t_{\text {.st }} r_{i}+\text { t.agr }_{i}+\text { t.other }_{i}\right)-(\text { c.vat } i+\text { c.gnp } i+\text { c.own })
$$

where $t$ stands for EU transfers or expenditures and $c$ for national contributions to the Union, both in per capita terms. On the EU revenue side, we distinguish between contributions linked to VAT revenues (c.vat) and national GNPs (c.gnp) and traditional "own" resources (c.own), comprised mostly by net tariff revenues. Expenditures are grouped into three categories: i) structural expenditures (t.str), comprised by the Regional, Social and Cohesion Funds, the Fisheries instrument and the guidance section of the Agricultural Fund, ii) agricultural expenditures (t.agr), which includes farm subsidies under the guarantee section of the Agricultural Fund, and iii) other expenditures (t.other), which includes expenditure under horizontal policies (e.g. R\&D programmes), transitory payments to new member states and various miscellanea. This last item also seems to include a small fraction of international cooperation programmes as allocated among member countries by the European Court of Auditors. Although in principle the expenditure data exclude the administrative costs of the various Union institutions, on the basis of the results for Luxembourg we cannot exclude the possibility that part of these costs may be included in t.other.

\footnotetext{
1 See for instance Sala-i-Martin and Sachs (1992), von Hagen (1992), Bayoumi and Masson (1995), de la Fuente (1997), Martin (2000) and Doménech, Maudes and Varela (2000) on the analysis of fiscal flows within federal or quasi-federal systems. The details of the specification vary. Some authors regress income after tax and transfers (instead of these last two variables) on gross income. Specifications in levels with cross-section data averaged over "long" periods are generally used to try to assess long-term redistributive effects, while specifications in differences with time-series data for each territory are used to determine the stabilization effects of the federal budget.
} 
Our budget data are taken from the Annual Report of the European Court of Auditors and are originally expressed in ecus. ${ }^{2}$ These figures are converted into national currencies and adjusted, together with incomes per capita, for differences in purchasing power. The resulting values are then normalized by average EU income per capita and expressed in differences with the corresponding (weighted) EU average. ${ }^{3}$ Thus, $n b_{i}$ is the difference between country i's net balance per capita and the average EU per capita net balance, measured as a fraction of average real EU income per capita. Notice that the average EU net balance will generally be different from zero because i) some EU expenditure is not allocated among member countries (e.g. administrative expenses) and ii) Union payments may differ from EU receipts in any given year (even more than budgeted expenditure) due to time lags in the execution of the budget.

Using the transformed data, we will regress member countries' relative net balances per capita and their various components (total transfers, total expenditures and each of the individual budget items) on relative income per capita in gross terms (i.e. GNP per head before contributions to or transfers from the Union budget) normalized in the same way as the other variables (i.e. measured in percentage deviations from average EU income per capita in purchasing power units). Since we are interested in redistributive (rather than stabilization) effects, we will run our regressions in levels, using cross section data, and repeat the exercise for each year in the sample period in order to examine the evolution of the system over time. Hence, for each year between 1986 and 1998, we estimate cross-section regressions of the form
(2) $n b_{i}=-\rho_{b} y_{i}+\varepsilon_{b i}$
(3) $t_{k i}=-\rho_{t k} y_{i}+\varepsilon_{t k i}$
and
(4) $c_{k i}=\rho_{c k} y_{i}+\varepsilon_{c k i}$

where $y_{i}$ is the relative gross income per capita of country $i, t_{k}$ and $c_{k}$ are the k-th transfer and contribution items, $\rho_{c k}$ and $\rho_{t k}$ the corresponding ("partial") redistribution coefficients and $\varepsilon_{k i}$ the regression residuals. Since these residuals capture the deviation from the amount that would correspond to each country on the basis of its income per capita under the allocation rule implicit in the regression line, we will refer to them as "adjusted" or "excess" partial balances. Notice that we have specified the regressions so that $\rho_{k}$ is positive if and only if the k-th budget item is redistributive, that is, if on average poor countries contribute less to the Union or receive more transfers from it than rich ones. Thus, $\rho_{b}=n b_{i} /\left(-y_{i}\right)$ is the relative net per capita transfer from the EU expressed as a fraction of the income differential with the EU average in a typical member state. The composition of the sample varies over time, reflecting the accession of new entrants and German unification.

Equations (2)-(4) are estimated by weighted least squares, weighting the observations by population size. Failure to weigh the observations would give misleading results due mostly to the effect of Luxembourg (see Figure 1 below). Our normalization of the data (in relative deviations from weighted

\footnotetext{
2 See Doménech, Maudes and Varela (2000) for a more detailed description of this data set. For 1998 we use the information provided by the European Commission in Allocation of 1998 EU operating expenditures by member states, since the annual report of the Court of Auditors for this year does not provide sufficient information about the allocation of the different expenditure programmes across countries.

${ }^{3}$ See the Appendix for a more detailed description of the normalization procedure and the construction of the variables used in equation (1).
} 
EU averages) implies that the sum of the weighted residuals in the estimated equations will be zero. Hence, the exercise of redistributing net balances across countries in a way that adds up is simpler than it would be in the unweighted case, where a counterfactual budget designed to eliminate deviations from the fitted line will typically not be feasible (because a reduction in per capita transfers to Ireland by one ecu will not pay for a reduction of the same amount in the per capita German contribution). The definition of our variables also ensures that the regression constant will be zero. This feature is convenient for two reasons. The first one is that it allows us to measure the progressivity of the system through a single parameter with a straightforward interpretation. The second is that, if we interpret the estimated regression as an allocation rule, this rule will specify that the budget should be neutral for countries of average income per capita. This seems sensible if we want to make normative recommendations as to the "fair" allocation of net contributions.

Another convenient feature of our specification is that the partial redistribution parameters $\left(\rho_{k}\right)$ associated with the different programmes and the adjusted partial balances (i.e. the residuals $\varepsilon_{i k}$ ) will add up, across equations for a given year, to the overall redistribution parameter $\left(\rho_{b}\right)$ and the adjusted net balance $\left(\varepsilon_{b i}\right)$ obtained from the overall redistribution equation. ${ }^{4}$ This property allows us to construct a simple indicator of the contribution of each budget item to redistribution across member states and to trace the sources of a country's net fiscal balance to the effects of specific programmes.

\section{3.- Results for $1986-98$}

Figure 1 displays the relationship between per capita net budget balances and relative GNP per capita across the member states of the EU in $1998 .^{5}$ The negative slope of the fitted regression line indicates that the net effect of the EU budget is redistributive, as net balances are, on average, positive in poor countries and negative in rich ones. The estimated redistribution coefficient is 0.0576 . Given the definition of our variables, this parameter indicates that, for a typical European citizen, the net effect of the EU budget is equivalent to a flat tax of $5.76 \%$ levied on the difference between his gross income (adjusted for purchasing power differences) and the EU average -- or to a subsidy of the same magnitude if his income is below average. Although this figure is very small compared with the degree of regional redistribution achieved by national fiscal systems (which typically lies around 0.30 for European and North American countries), it is achieved with a volume of expenditure only slightly above 1\% of GNP (as compared to figures between 30 and 60\% of GNP for national fiscal systems). In this sense, then, the EU budget is a rather effective instrument for redistribution among member states.

\footnotetext{
4 See the Appendix for a derivation of these properties.

5 Our results are slightly different from those reported in a previous version of this paper (de la Fuente and Doménech (1999)) because i) we have extended the sample period by one year and ii) we now use GNP per capita rather than GDP as the regressor in our our redistribution equations. Since our emphasis is on income (i.e. ability to pay), rather than on productivity, this variable seems preferable. On the other hand, the change makes very little difference in terms of the overall message of the paper, although it is important when evaluating the excess balances of some specific countries (especially Ireland).
} 
Figure 1: Relative net national balances per capita vs. relative per capita incomes, 1998

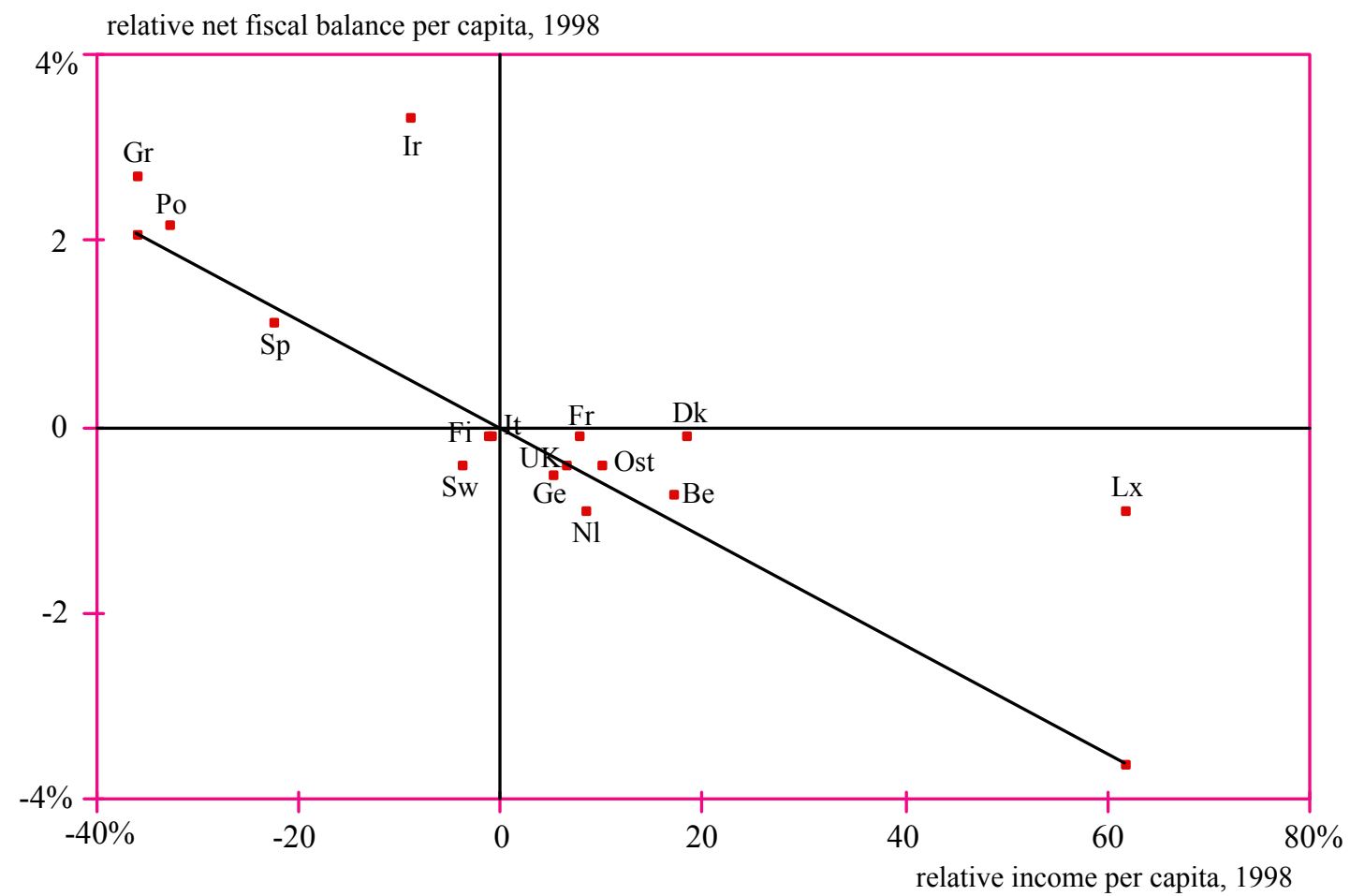

- Legend: $\mathrm{Gr}=$ Greece, Po = Portugal; Sp = Spain; Ir = Ireland; Fin = Finland; Sw = Sweden; UK = United Kingdom; It = Italy; $\mathrm{Nl}=$ Netherlands; Fr = France; Ge = Germany; Ost = Austria; Be = Belgium; Dk = Denmark; Lux = Luxembourg.

- Note: estimation by OLS with observations weighted by population size. The fitted equation is of the form $n b_{98}=$ $-0.0576 y_{98}$.

The figure shows that the net expenditures of the European Union are distributed rather unevenly across its members. While an important part of this variation (around two thirds) is systematically related to per capita incomes, the large deviations we observe from the regression line indicate that countries with similar income levels are often treated very differently. The most obvious outliers are Ireland and Luxembourg, whose net balances are, respectively, 2.8 and 2.6 points higher than they "should" be on the basis of the allocation criterion implicit in the fitted regression line. Moreover, the distribution of adjusted net balances given by the residuals of the regression is very different from that of unadjusted balances. After correcting for income, for instance, Luxembourg, Denmark, France and Belgium display relatively large positive net balances, while the residual for Spain is negative and those for Germany and the UK are close to zero.

As we go back in time, the picture does not change very much in qualitative terms. The most noteworthy development is the sharp increase in the redistribution parameter over most of the sample period. As shown in Figure 2, the value of $\rho_{b}$ increases almost threefold between 1986 and 1993, and levels off thereafter. The evolution of the dispersion of the adjusted net balances, which can be interpreted as an indicator of the "arbitrariness" of budget allocations (relative to the redistributive criterion implicit in the estimated equation), is shown in Figure 3. On average across the period, the 
typical country is about 0.45 percentage points of per capita EU income away from the net balance dictated by its income level. This figure increases significantly from 1988 to 1993 and declines thereafter.

Figure 2: Evolution of the redistributive impact of the EU budget (overall redistribution coefficient, $\rho_{b}$ )

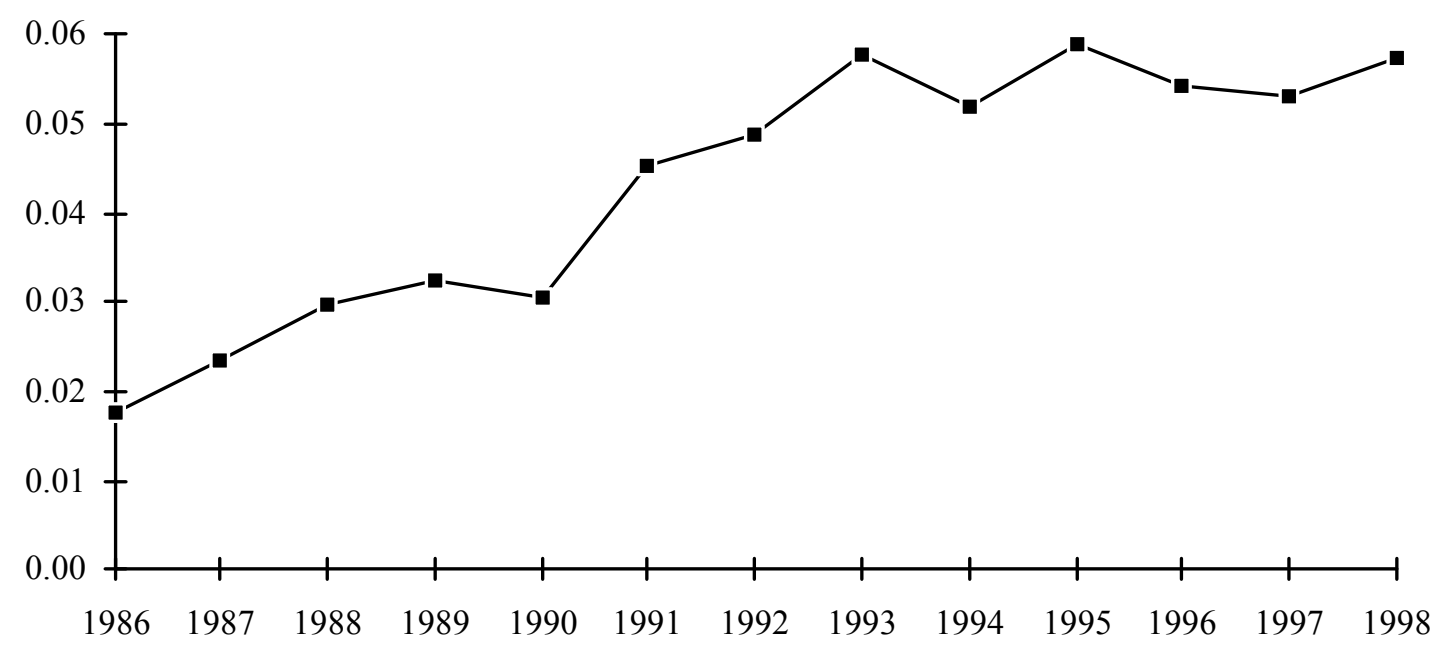

Figure 3: Evolution of the dispersion of adjusted net budgetary balances

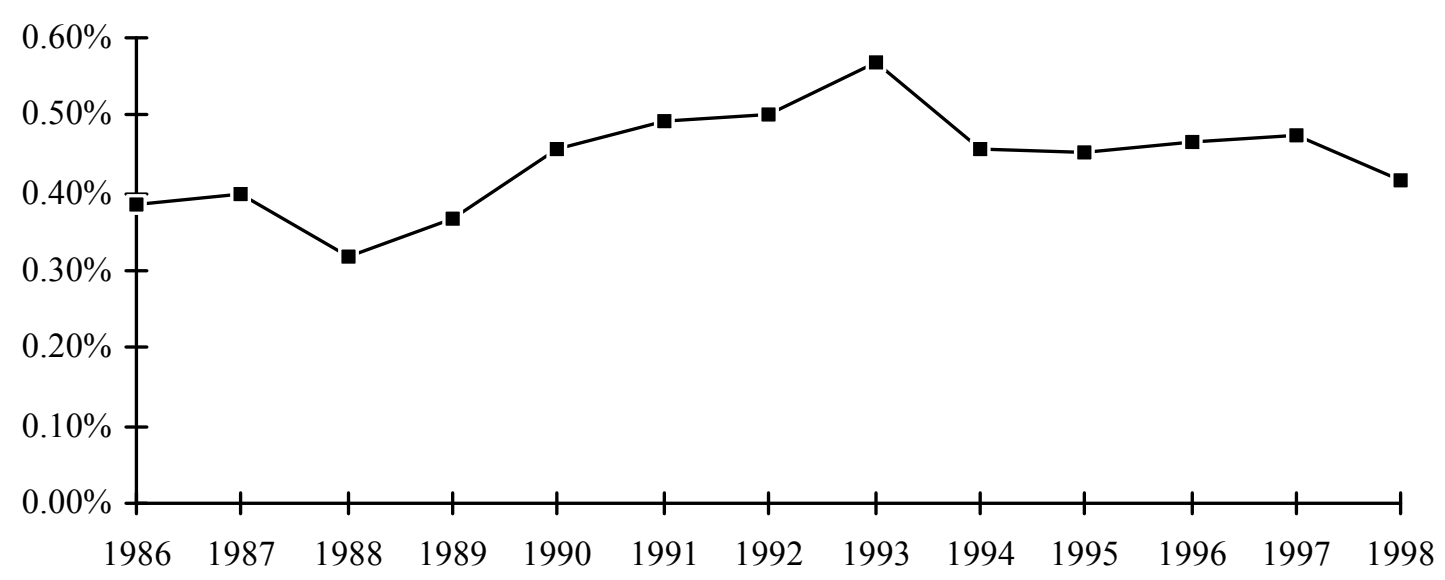

- Note: weighted standard deviation of the residuals of the redistribution regressions for net budget balances.

Working with averages over time, the distribution of net balances across countries resembles the one observed in 1998, although with some changes in the ranking. As shown in Figure 4, Ireland, Luxembourg, Greece, Denmark, Belgium and France are the main beneficiaries of the EU budget after adjusting for per capita income. On the other end of the scale, Sweden, Spain, Finland, the UK and Germany display the largest negative adjusted balances. 
Figure 4: Gross and adjusted net fiscal balances per capita, averages over the entire sample period

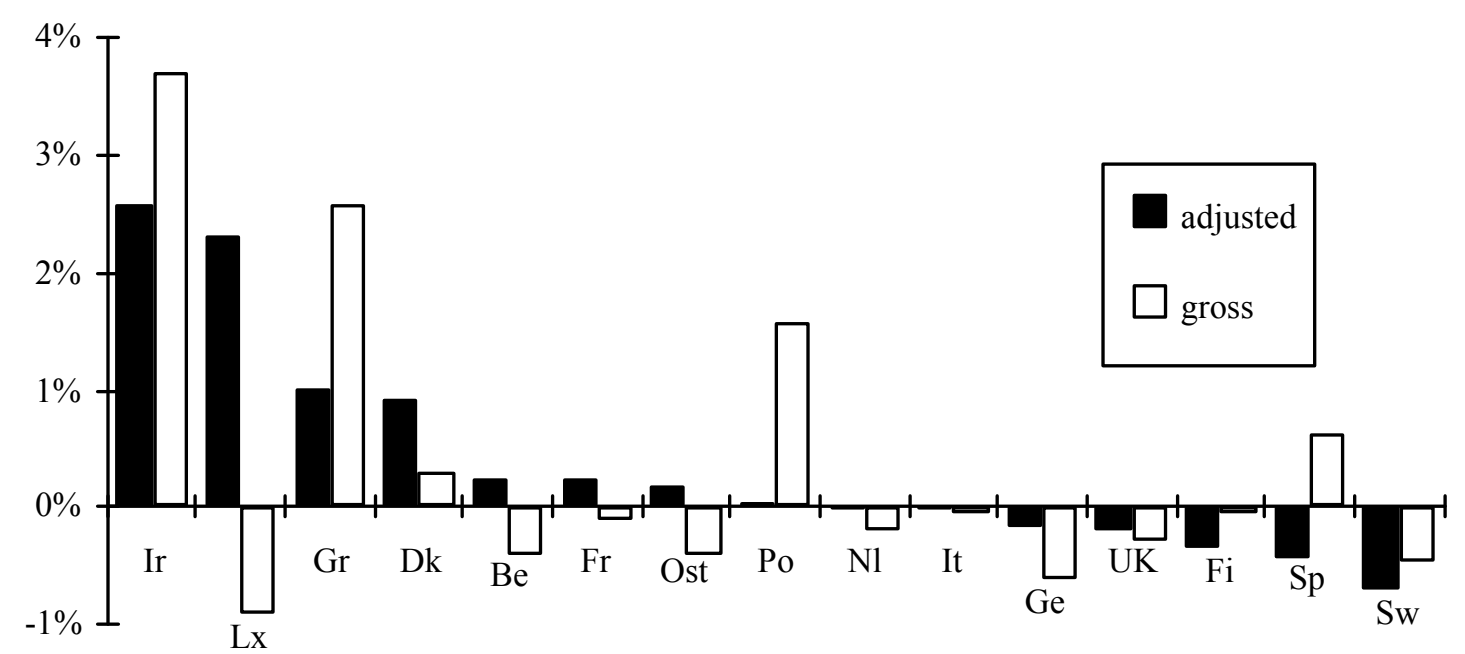

Note: The gross balance is the net surplus per capita expressed as a fraction of average EU income per capita. The adjusted net balance is the residual of a regression of the previous variable on relative income per capita, defined as income per capita corrected for PPP and measured in percentage deviations from the EU average. Both variables are averaged over time for each country, starting in 1986 or in the year in which the country joined the EU.

Figure 5: Decomposition of the overall redistribution coefficient: transfers vs. contributions

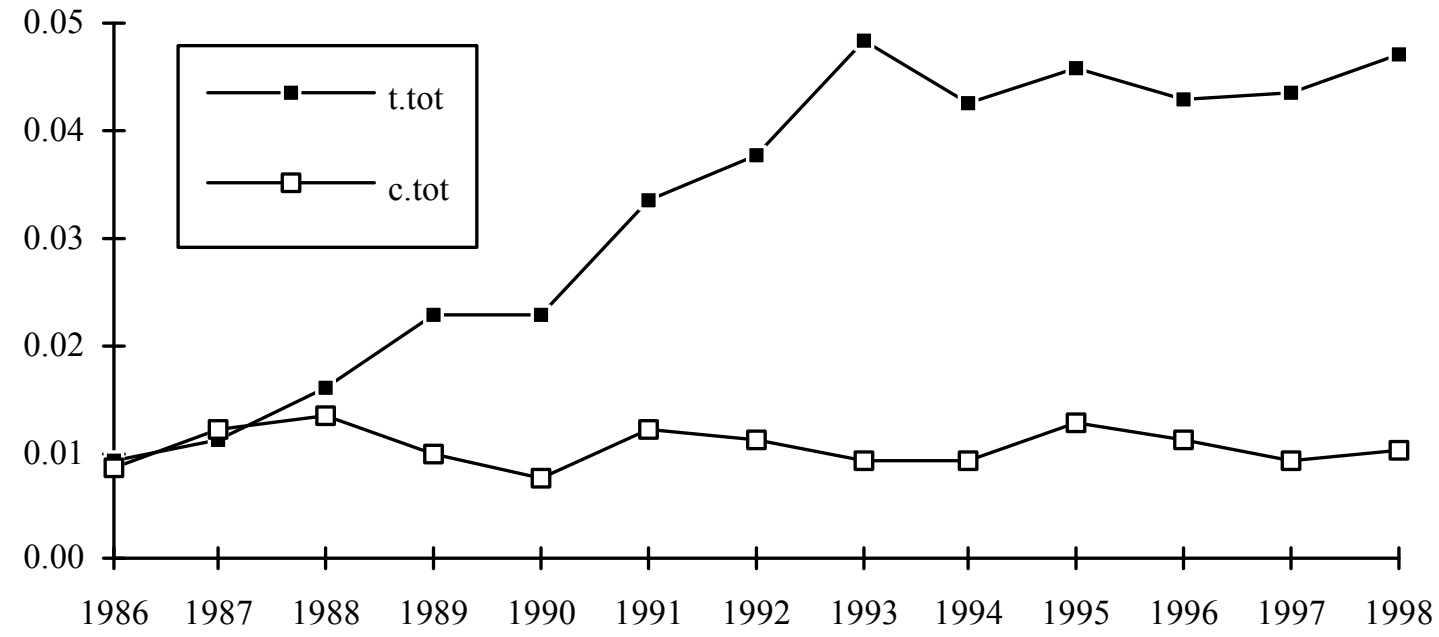

The redistributive effects of the EU budget come from both its expenditure and revenue sides. As shown in Figure 5, where we decompose the total redistribution coefficient into its transfers and contributions components, the first of these parameters was typically much larger than the second one. Indeed, EU expenditures have become increasingly progressive with the growth of structural spending, which being heavily concentrated in poorer countries, is the most redistributive of all budget items. In 1998, this programme accounted for over $60 \%$ of the total redistribution effect with 
Figure 6: Decomposition of the redistribution coefficient for total transfers structural vs. agricultural transfers and other expenditures

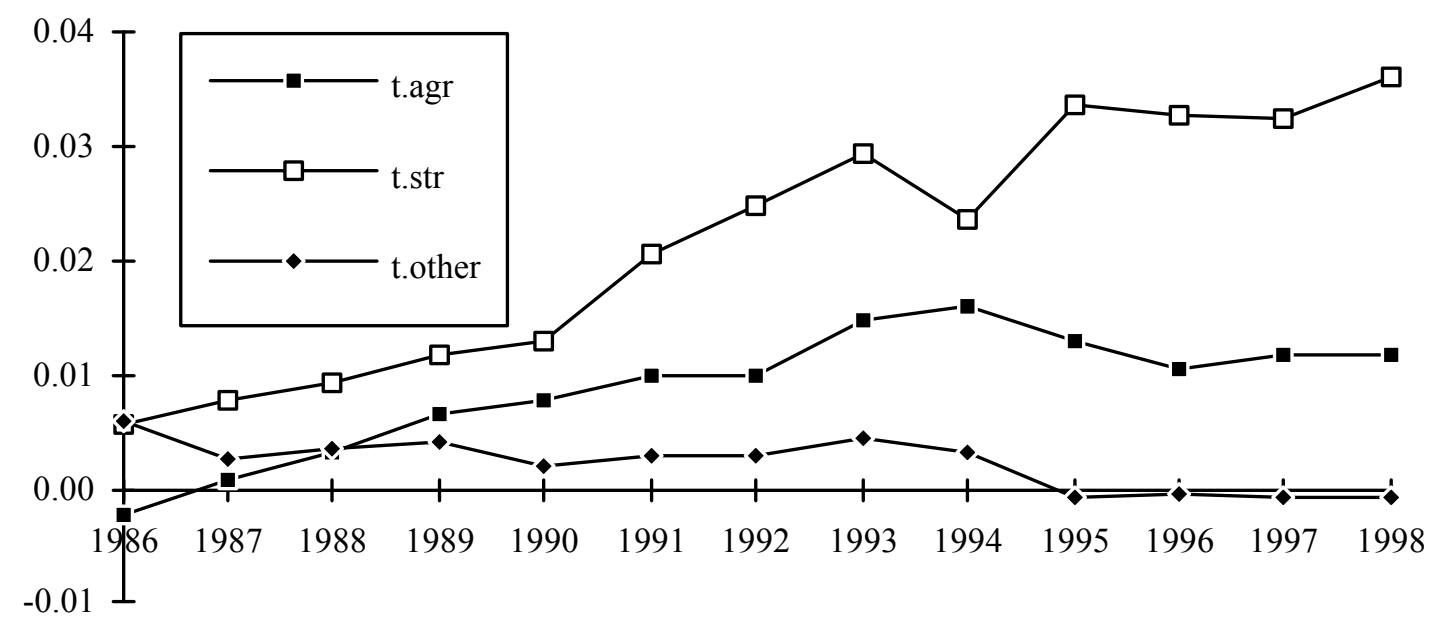

Figure 7: Decomposition of the redistribution coefficient for total contributions VAT, GNP and own resources

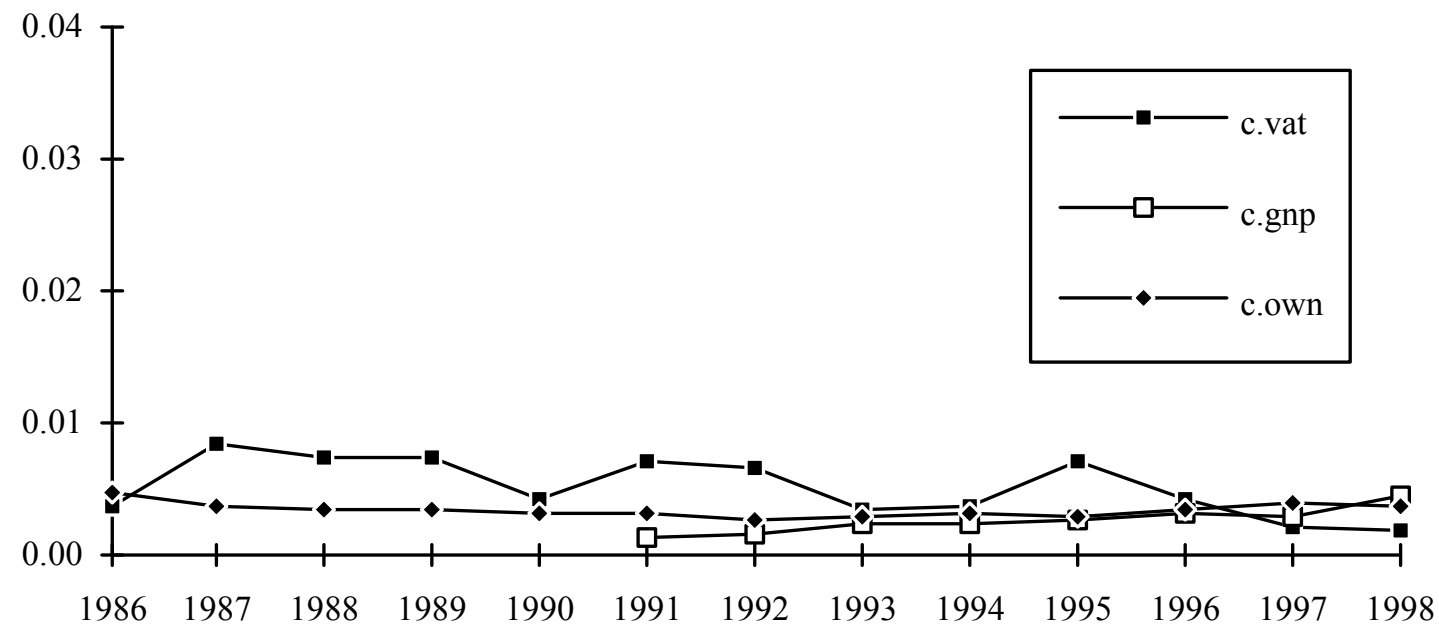

about one third of total expenditure. The farm subsidy programme is also redistributive, but only because the weight of agricultural employment is considerably larger in the poorer member states. Payments per farmer, on the other hand, vary widely across countries and, with the exception of Ireland, do not favour the poorer states. (See Figure 8). EU revenues, on the other hand, are roughly proportional to income (see Figure 7). ${ }^{6}$ Hence, they are somewhat redistributive (because the rich pay more per capita in absolute terms), but their impact is quite limited.

6 See Doménech, Maudes and Varela (2000). 


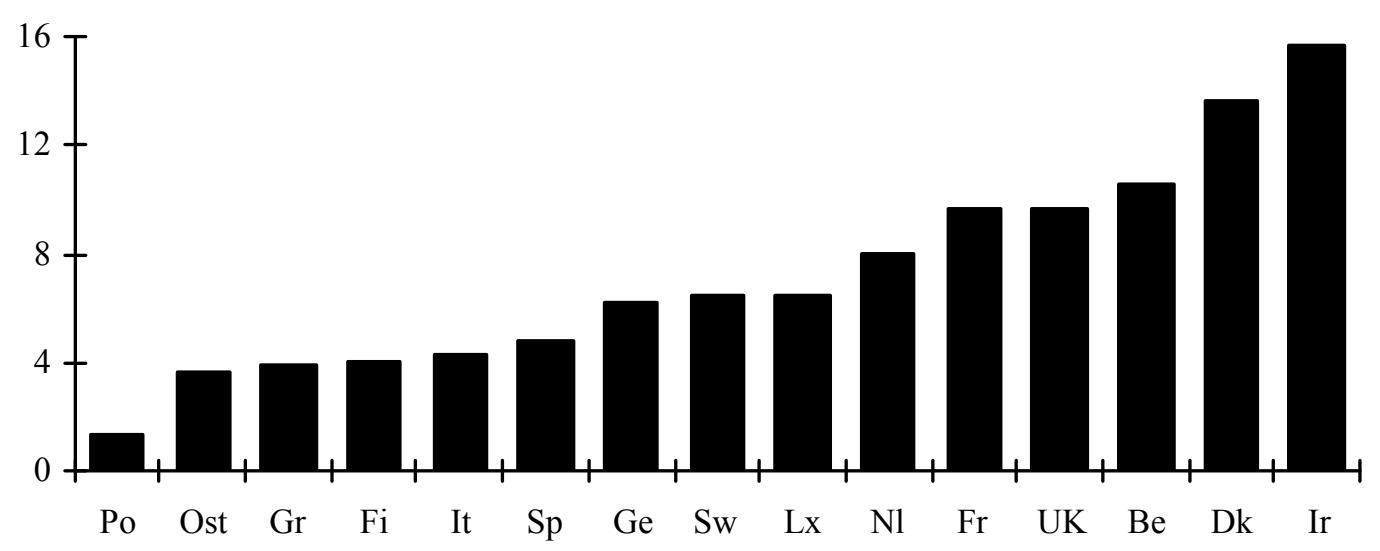

- Source: The Economist, Feb. 20th 1999, p. 30, with data from the European Commission.

Figures 9 and 10 show the sources of national net balances working with averages over each country's period of membership in the Union since 1986. Figures 11 to 19 (included at the end of the text) show the year-by-year evolution of the adjusted total and partial balances for each country in the sample. A few items deserve special comment. The UK's net VAT contribution is very small because a large fraction of it is rebated under the "British abatement" in order to reduce this country's net deficit with the EU. Holland and Belgium display large positive residuals in their contributions to the Community's "own" resources (c.own) because a disproportionate share of imports from outside the EU comes through their ports, generating a large amount of tariff revenue. Luxembourg, on the other hand, presents exactly the opposite situation (because very few non-EU imports come directly into the country) but displays a very large VAT contribution, presumably because of taxes on financial transactions residenced there for fiscal reasons. Large tariff revenues in Ireland, finally, may be due in part to the importation of intermediate goods by multinationals that have production facilities in this country and export final goods to the rest of the Union.

On the expenditure side, farm support programs have benefited Ireland, Greece, Denmark, the Netherlands, Belgium and France at the expense of Portugal, Spain, the UK, Sweden and Finland. The Dutch and Belgian figures, however, are probably inflated by rebates on exports shipped through their ports but originating in other Union countries. Adjusted structural expenditure has been highest in Luxembourg, Ireland and Portugal and lowest in Sweden, Finland, Spain, Holland and the UK. Finally, other expenditures have gone mostly to the new entrants as well as to Belgium and Luxembourg. As noted above, the size of this item makes us suspect that it may include some administrative expenses. 
Figure 9: Adjusted partial fiscal balances: revenue side of the EU budget averages over each country's period of membership in the Union

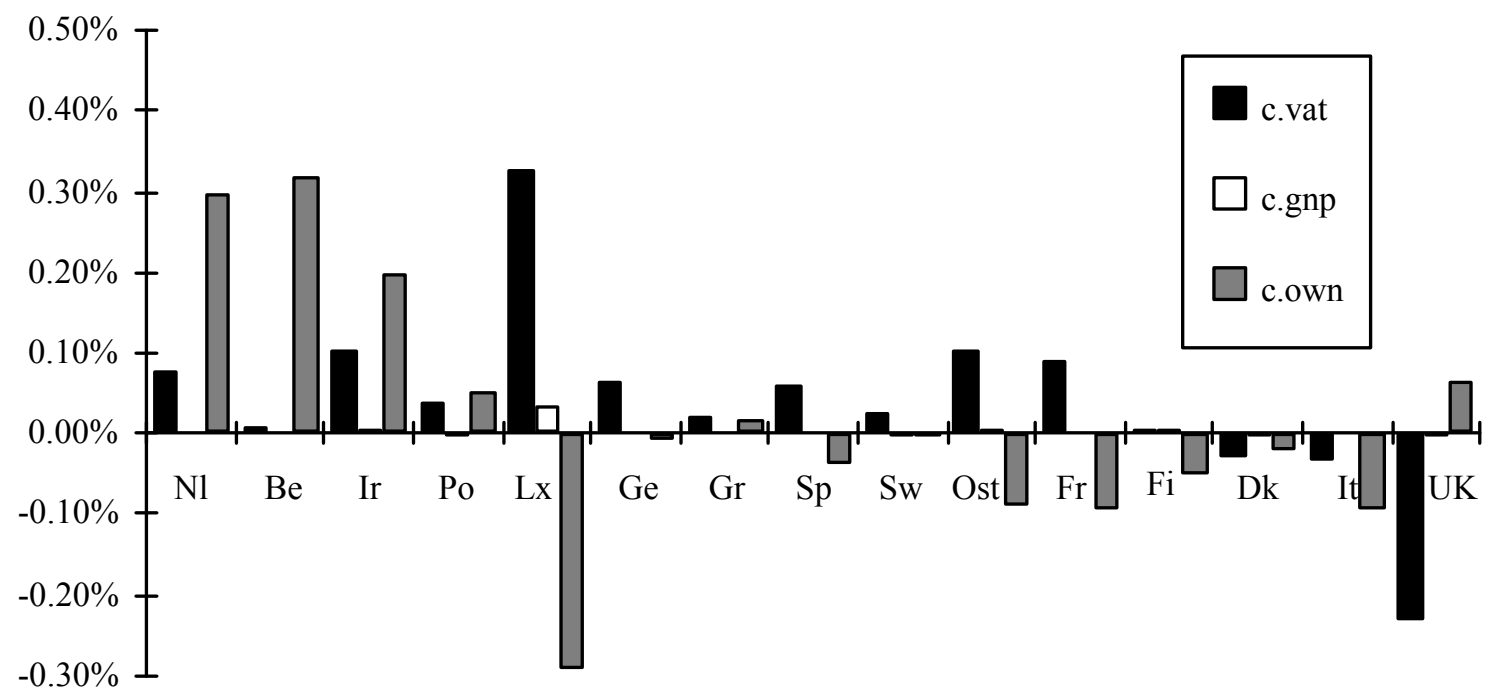

Figure 10: Adjusted partial fiscal balances: expenditure side of the EU budget averages over each country's period of membership in the Union

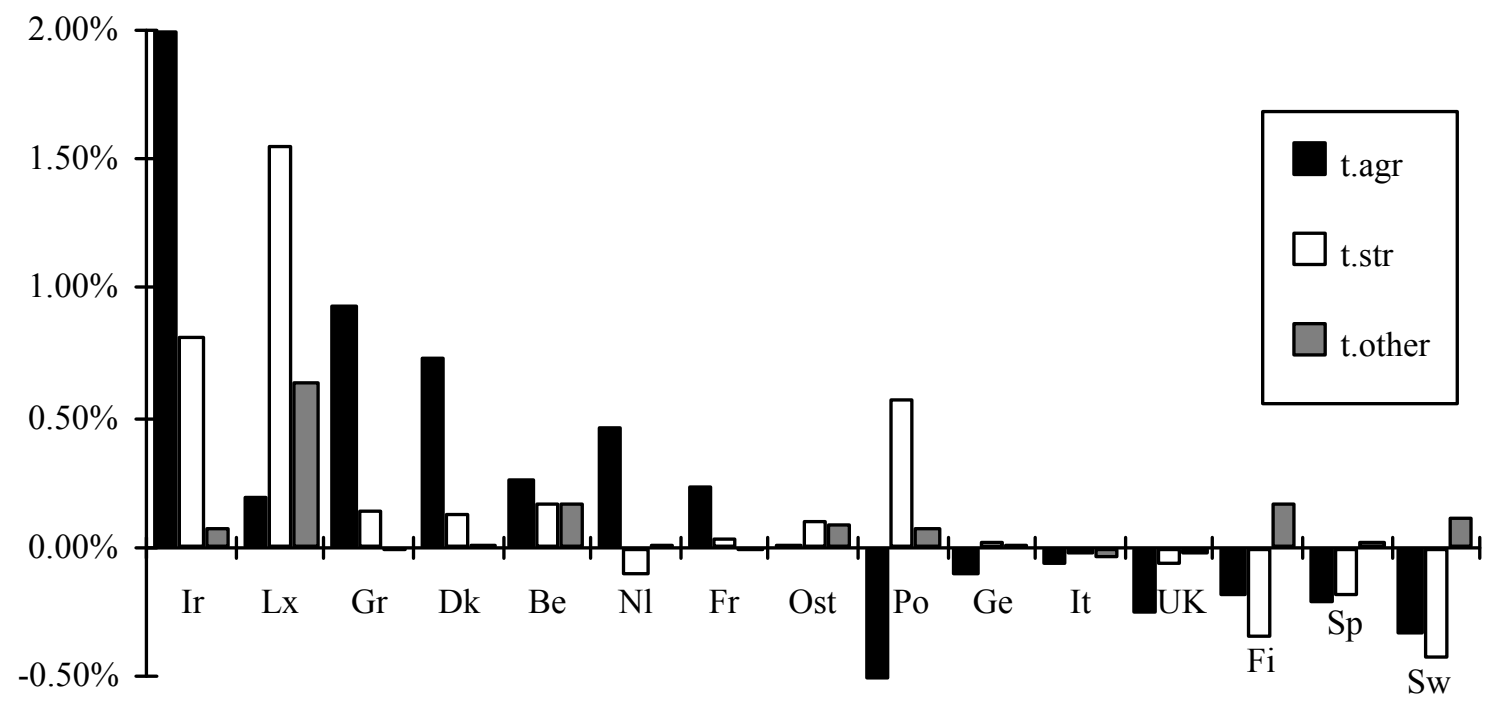

In summary, our analysis shows that the overall redistributive impact of the fiscal flows across EU members is considerable, given the small size of the Union budget, and that it comes mostly from its structural expenditure programmes. The degree of redistribution, moreover, has increased significantly over time, although it has tended to stabilize in recent years. On the other hand, the distribution of net contributions across countries shows large and persistent deviations from the average pattern of redistribution. To the extent that this pattern embodies a consensus on what may be considered a fair allocation of the fiscal costs and benefits of Union membership, the existence of such large "excess" 
surpluses and deficits is a serious matter for concern and would seem to lay at the root of the ongoing budget dispute. While it is certainly true that net fiscal transfers capture only a part (and probably a small one) of the benefits of membership in the European Union, they are also the most visible and easily quantifiable aspect of such benefits. As a result, public and government views on the overall fairness of the system are likely to depend critically on the extent to which their allocation is perceived to be equitable. Ensuring that it is so should be an important goal of Community budget policy.

In this context, the analysis we have just conducted may be of interest as a tool for making operational a simple equity criterion derived from the Union's commitment to the principle of cohesion. Our procedure, in particular, allows us to decompose net national balances into two parts: one which may be attributed to wealth differences, taking as given the "revealed" average degree of redistribution in the system, and a residual or adjusted balance that measures the deviation from the allocation rule implicit in the regression line fitted to the observed net balances. It seems likely that progress in budget negotiations will be easier to make if these two different components are discussed separately.

\section{4.- A proposal for budget reform and some reflections on the Berlin Summit}

The recent negotiations on the EU's financial perspectives for the period 2000-2006 have brought out into the open wide discrepancies among EU members concerning budgetary matters. In the months preceding the 1999 Berlin summit, discussions focused on the national and functional allocation of EU revenues and expenditures. While most countries agreed on the need to maintain the existing ceiling on expenditure (set at $1.27 \%$ of the Union's GNP), there was considerable dis-agreement among them on how this revenue should be raised and spent. The richer members of the EU, led by Germany, pressed hard for a reduction of their net contributions, while the poorer ones argued that their positive net balances should be preserved on equity grounds. Disparate national interests were also clearly discernible in proposals for the restructuring of farm and structural programmes and in the discussions about their funding.

In addition to the unavoidable conflict between national interests, perhaps the most important obstacle to a budget consensus is the lack of a shared and operational equity criterion for the allocation of net budget contributions. In this section we explore the implications of adopting as such a criterion the redistribution rule implicit in the net balance equations we have estimated in previous sections. After outlining a budget procedure consistent with this rule and discussing some of its advantages, we examine how the 1998 budget situation changes when seen from this perspective, rather than in terms of unadjusted balances, and analyze the impact of the Berlin agreement on the horizontal and vertical equity properties of the EU budget. 


\section{A proposal for budget reform}

Our proposal involves linking fiscal balances to income per capita through a simple rule that reflects an evolving consensus on the desirable degree of redistribution and treats countries with similar income levels in a similar way. To make this principle operational, budget negotiations should be approached in several stages. First, an agreement should be reached on the overall amount of resources available to the Union, on the mechanisms for its financing and on the desired degree of redistribution. Second, indicative net balances should be computed for each of the member states on the basis of their per capita incomes and an agreed-upon redistribution coefficient. Third, budget allocations to specific expenditure programmes should be made on the basis of the relevant policy objectives. Finally, structural spending and, if necessary, compensatory payments or rebates should be set so as to obtain the desired redistributive outcome. The procedure will probably work best if it is applied in an incremental way, i.e. as a tool for identifying the desired direction of change from the status quo.

In the current situation, it is probably sensible to take as given the overall ceiling on expenditure and the current degree of redistribution and concentrate on the gradual elimination of "excess" balances. The rationale for this objective is clear, as there is very little justification on equity grounds for a EU budget which does not treat equally countries with similar levels of wealth. This, of course, applies only to net balances. Specific budget items, with the possible exception of structural spending, should be set and evaluated in terms of the policy goals involved, and not in terms of their redistributive effects. But the principle of cohesion, and more importantly, the political feasibility of the Union and its legitimacy, require that the distribution of net benefits be inversely related to income levels. If this objective cannot be reasonably well met under the existing budget structure, it may be advisable to introduce a compensatory mechanism (in the form of rebates or surcharges on GNP contributions, for instance) that ensures overall equity. ${ }^{7}$

We believe this procedure will also improve the quality of budget decisions by changing in a positive way the incentives faced by national governments. Under the current situation, with national contributions largely set in advance, community expenditures are perceived as having a zero marginal cost to national governments. Hence, ministers will enter council meetings (especially sectoral ones), with the incentive to fight for every possible increase in spending favouring their own countries -- and this includes programmes they would probably not be willing to finance with their own budgets. If net balances are set in advance, so that expenditure gains in any given programme will have to be financed at the margin by national budgets, this perverse incentive disappears.

To illustrate the implications of our proposal, Table 1 examines the redistributive impact of the 1998 EU budget from two alternative perspectives. The left half of the table summarizes what may be called

7 It may be advisable, however, to limit the possibility of obtaining cash rebates to countries that are net contributors to the Union budget, while subjecting compensatory payments to net beneficiaries to Commission control. These payments may, for instance, adopt the form of increased allowances for structural programmes in order to ensure that EU resources are spent in ways that promote development. 
the "rich country view" going into the Berlin Summit, while the right half shows how the picture changes when we correct for income per capita. As shown in the first block of columns, the $1998 \mathrm{EU}$ budget transferred around 18 billion ecus from relatively rich to relatively poor member countries. Germany paid almost one half of this amount, followed by the UK and the Netherlands, and the net beneficiaries were the four "cohesion countries", with Spain absorbing over $40 \%$ of the total surplus. Figures of this nature have often been invoked to support calls for a "more equitable" distribution of fiscal burdens, understood as a reduction in the deficits of the main net contributors financed, presumably, by the curtailment of cohesion policies. In this manner, progress towards budgetary equity is often linked to the reduction of north-south fiscal flows.

Table 1: Distribution of relative budgetary balances with the EU, 1998

\begin{tabular}{|c|c|c|c|c|c|c|c|c|c|}
\hline \multicolumn{3}{|c|}{ total gross balance } & \multicolumn{2}{|c|}{ per capita gross } & \multicolumn{2}{|c|}{ per capita adjusted } & \multicolumn{3}{|c|}{ total adjusted balance } \\
\hline & Mecus & $\%$ total & & ecus & & ecus & & Mecus & $\%$ tot \\
\hline$G e$ & $-8,089$ & $-44.5 \%$ & $L x$ & -179 & $S w$ & -128 & Ge & $-3,529$ & $-34.7 \%$ \\
\hline$U K$ & $-4,047$ & $-22.3 \%$ & $N l$ & -168 & $\mathrm{Nl}$ & -80 & It & $-2,239$ & $-22.0 \%$ \\
\hline$N l$ & $-2,618$ & $-14.4 \%$ & $B e$ & -114 & Ge & -43 & $S p$ & $-1,369$ & $-13.5 \%$ \\
\hline$B e$ & $-1,162$ & $-6.4 \%$ & Ge & -98 & It & -39 & $N l$ & $-1,254$ & $-12.3 \%$ \\
\hline$S w$ & -812 & $-4.5 \%$ & Sw & -92 & $S p$ & -35 & $S w$ & $-1,137$ & $-11.2 \%$ \\
\hline It & -604 & $-3.3 \%$ & $U K$ & -69 & $F i$ & -35 & $U K$ & -467 & $-4.6 \%$ \\
\hline Ost & -549 & $-3.0 \%$ & Ost & -68 & $U K$ & -8 & $F i$ & -178 & $-1.7 \%$ \\
\hline$F r$ & -103 & $-0.6 \%$ & $D K$ & -13 & Ost & 36 & $L x$ & 221 & $2.2 \%$ \\
\hline$L x$ & -76 & $-0.4 \%$ & It & -11 & Po & 57 & Ost & 289 & $2.8 \%$ \\
\hline$D K$ & -68 & $-0.4 \%$ & $F i$ & -9 & $B e$ & 60 & Po & 567 & $5.6 \%$ \\
\hline$F i$ & -47 & $-0.3 \%$ & $F r$ & -2 & $F r$ & 71 & $B e$ & 609 & $6.0 \%$ \\
\hline$I r$ & 2,328 & $12.8 \%$ & $S p$ & 197 & $G r$ & 121 & $D k$ & 994 & $9.8 \%$ \\
\hline Po & 3,167 & $17.4 \%$ & Po & 316 & $D k$ & 188 & $G r$ & 1,267 & $12.5 \%$ \\
\hline$G r$ & 4,922 & $27.1 \%$ & $G r$ & 469 & $L x$ & 518 & Ir & 2,066 & $20.3 \%$ \\
\hline$S p$ & 7,759 & $42.7 \%$ & Ir & 624 & $I r$ & 554 & $F r$ & 4,160 & $40.9 \%$ \\
\hline $\begin{array}{l}\text { tot. } \\
\text { redist. }\end{array}$ & 18,176 & & & & & & & 10,174 & \\
\hline
\end{tabular}

- Note: per capita gross balances are expressed in relative terms, i.e. as differences from the average per capita budget balance for the whole of the EU. Multiplying this figure by the population of each country we obtain the total gross balance given in the first column. The adjusted per capita balance is the residual of a redistribution regression, as explained in previous sections, times average EU (nominal) income per capita, and the total adjusted balance is obtained by multiplying this figure by the population.

In contrast, our analysis suggests that, although some complaints about excessive contributions are quite justified, an important part of the problem has to do with the inequitable allocation of budget burdens across rich countries. While it is certainly legitimate to argue that the current degree of progressivity of the system may be too high, there is plenty of room for improving the horizontal equity of budget allocations without reducing the overall level of redistributive effort. The right half of Table 1 shows the adjusted relative per capita net balances of the different member states in 1998 and the implied "excess surpluses" in millions of 1998 ecus. As can be seen in the table, moving to the "fair" 
allocation described by the estimated redistribution regression would involve a transfer of approximately ten billion ecus across member states. In absolute terms, the main beneficiaries would be Germany, Italy, Spain, the Netherlands and Sweden, at the expense of France, Ireland, Greece, Denmark and Belgium. It is worth noting that three fourths of the required transfers would flow across rich countries. The net balance in favour of the Cohesion Four would decline by a total of 2,551 Mecus, with $80 \%$ of that quantity coming from Ireland. Spain's net surplus, moreover, would actually increase by about a billion ecus.

Our estimates should be refined in a number of ways before they can be used as the basis for an equitable reallocation of resources. First, all EU expenditures should be allocated among member states in some sensible way. The reason is that our procedure implicitly allocates such expenses on a per capita basis (through the average EU net balance, which enters into the computation of the net relative balances used in the regressions). On equity grounds, it seems preferable to allocate most "overhead" expenses, including foreign aid, in proportion to GNP. In the case of operating expenses (such as salaries and purchases of goods and services), the allocation should also be related, although only in part, to the location of the various EU institutions and to the nationality of its personnel for, while it is true that their benefits accrue in principle to all EU citizens, all countries would prefer to have such institutions located in their own territory. Finally, export rebates and the cost of price support interventions in agricultural markets should probably be allocated in proportion to the production of the relevant agricultural commodities. On the revenue side, tariff receipts should be allocated in proportion to GNP, rather than on the basis of the port of entry of non-EU imports. Finally, our computations should be adjusted in order to take into account the need to gradually free resources in order to finance the accession of new member states.

\section{The impact of the Berlin budget agreement}

While the reallocation of net balances in greater accordance with equity criteria was one of the central issues in the Berlin budget negotiations, this objective seems to have been approached in a rather roundabout way. Rather than focusing directly on net balances, member states have argued mostly about how much to reduce expenditure on agricultural and structural programmes (relative to the Commission's original proposals) in order to finance a reduction of the fiscal deficits of net contributors to the system and increase the margin for accession-related expenditure. As shown in Figure 20, the Berlin agreement involves a steeper decline in both structural and agricultural expenditure in current member states, measured as a fraction of EU15 GNP, than was originally proposed by the Commission in Agenda 2000. Relative to 1999 spending levels, the cut in structural programmes is about twice as large as the one in the CAP: while the share of structural expenditure in GNP will decline by 31\% between 1999 and 2006 (from $0.46 \%$ to $0.32 \%$ ), the reduction in agricultural spending will be only of $16 \%$ (from $0.54 \%$ to $0.45 \%$ ). 
Figure 20: Berlin budget agreement vs. Agenda 2000

Appropriations as a percentage of EU15 GNP

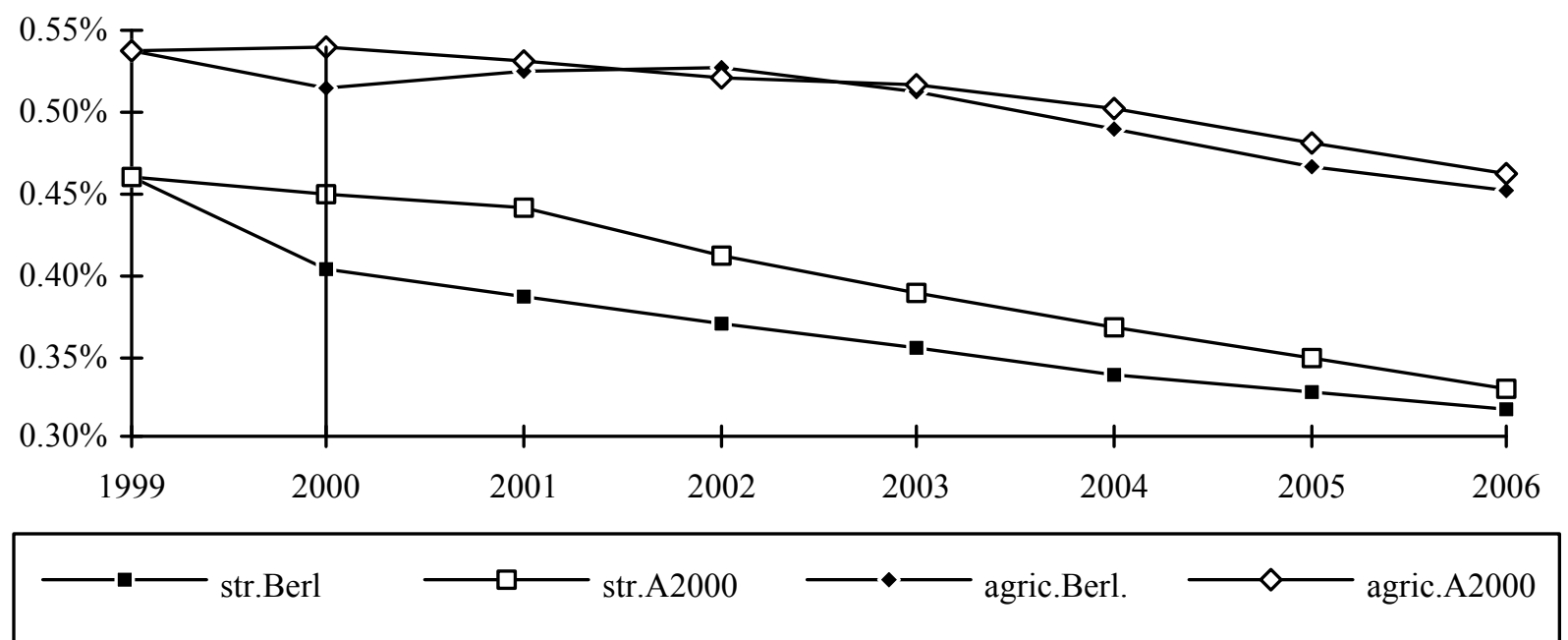

- Sources: European Commission (1997) and European Union (1999).

Figure 21: Expected percentage change in structural expenditure by country average 1994-1999 vs. average 2000-06

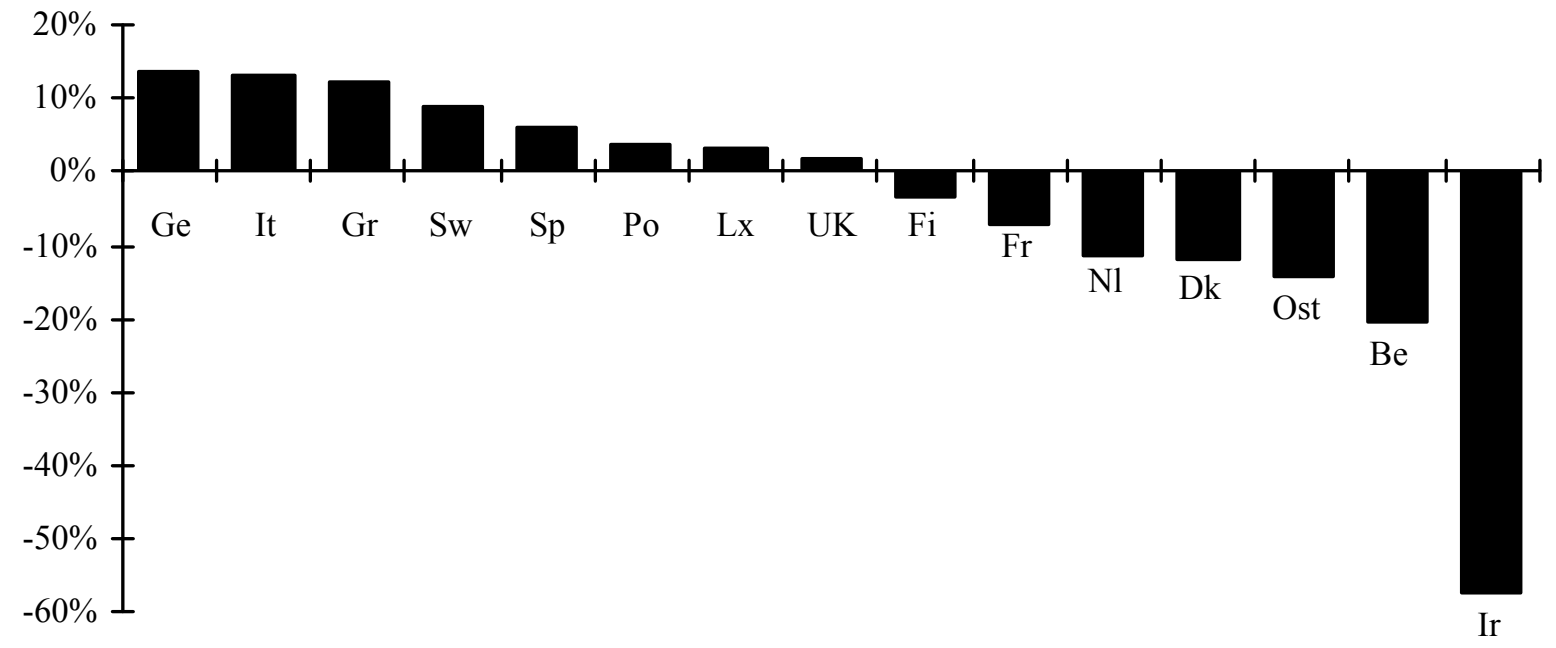

- Source: Spanish Ministry of Economic Affairs and Finance with data from the EU Commission.

Since structural programmes are by far the most progressive component of the EU budget, it may be expected that the degree of redistribution across (current) member countries will decrease in the years to come. This outcome is not inevitable, however, for at least two reasons. The first is that income disparities across member countries have been falling over time and will, presumably, continue to do so in the future. Hence, the need for cohesion policies is likely to decrease, making it possible to maintain the current level of redistributive effort at a lower expense. Secondly, expenditure cuts may not reduce the level of redistribution if remaining resources are allocated more tightly in proportion to 
income, as seems to be the Union's intention given its insistence on the greater concentration of structural aid.

The existing data on the planned geographical allocation of EU receipts and expenditures does not permit at this time a comprehensive evaluation of the equity implications of the current financial perspectives. Although overall expenditure and revenue targets have been published, explicit guidelines for national allocations are available only for structural expenditures. ${ }^{8}$ Figure 21 shows the expected percentage change in average annual structural aid to each member country over the amount received during the period 1994-99. In general terms, structural transfers are expected to increase more in countries that currently display negative adjusted balances, therefore contributing to increase the horizontal equity of budget allocations. ${ }^{9}$

Using the available data, we have performed some indicative calculations that attempt to gauge the horizontal and vertical equity implications of the current financial perspectives. Since EU revenues are roughly proportional to national income and it is difficult to predict their country-by-country evolution, we focus exclusively on the expenditure side of the budget. For structural programmes we use the indicative national allocations mentioned above. As for agricultural subsidies and other expenditures, we only have data on average planned yearly expenditure for the entire EU15. Since there are no obvious reasons to expect major changes in their allocation, we distribute these expenditures across countries using the observed national shares in each type of spending during the period 1996-98. In this manner, we attempt to capture redistributive effects arising from changes in the scale of these programmes. Following the same procedure as in previous sections, the resulting budget items, properly normalized, are regressed against gross relative income per capita in 1999 to obtain the relevant redistribution coefficients and excess balances. ${ }^{10}$

We will compare the results of this exercise with three alternative benchmarks in an attempt to determine how the current budget agreement compares, in terms of its degree of redistribution and horizontal equity properties, with i) the status quo just prior to its inception and ii) the previous financial perspectives. In the first case, the relevant benchmark is the 1998 expenditure situation. In the second case, we would in principle like to regress average expenditure over the period 1994-99 on 1993 per capita incomes in order to quantify the ex-ante equity properties of the previous framework. Things are complicated, however, by the fact that, since Union membership changes with the accession of

\footnotetext{
8 The national allocations of structural fund resources earmarked for Objectives 1-3 and the Fisheries instrument have been published as official Commission decisions (numbers 199/501/CE, 199/504/CE, 199/505/CE and 1999/500/CE). These resources represent $86.2 \%$ of the total structural expeditures contemplated in the current financial perspectives. Our analysis is based on unofficial figures provided by the Spanish Ministry of Economic Affairs that are compatible with these EC decisions but seem to include all structural expenditure as well as the Cohesion Fund. Given the nature of these data, our results should be interpreted with some precaution.

${ }^{9}$ The correlation between these two variables is -0.60 .

10 Our 1999 GNP figures are estimates taken from the Autumm 1999 issue of the Annual Macroeconomics Database of DG II of the European Commission. To approximate "gross" GNP (before EU transfers and contributions), we subtract from the "net" GNP given in this source the average net balance of each country with the Union during the period 1996-98, measured in 1999 euros.
} 
Austria, Sweden and Finland in 1995, budget allocations for new entrants cannot be meaningfully related to their 1993 income levels. To get around this problem, our redistribution equation combines two different types of observations in a single regression. For the original EU12 countries, the dependent variable is average expenditure over the whole period and the regressor is 1993 gross income per capita. For the new entrants, by contrast, we regress average EU expenditure over 1996-98 (excluding 1995 which is a rather atypical year) on 1995 gross income per capita. As an alternative, we also report a regression of average 1996-98 expenditure on 1995 income for all countries.

Figure 22: Expenditure-side redistribution coefficients: Berlin agreement vs. three alternative benchmarks

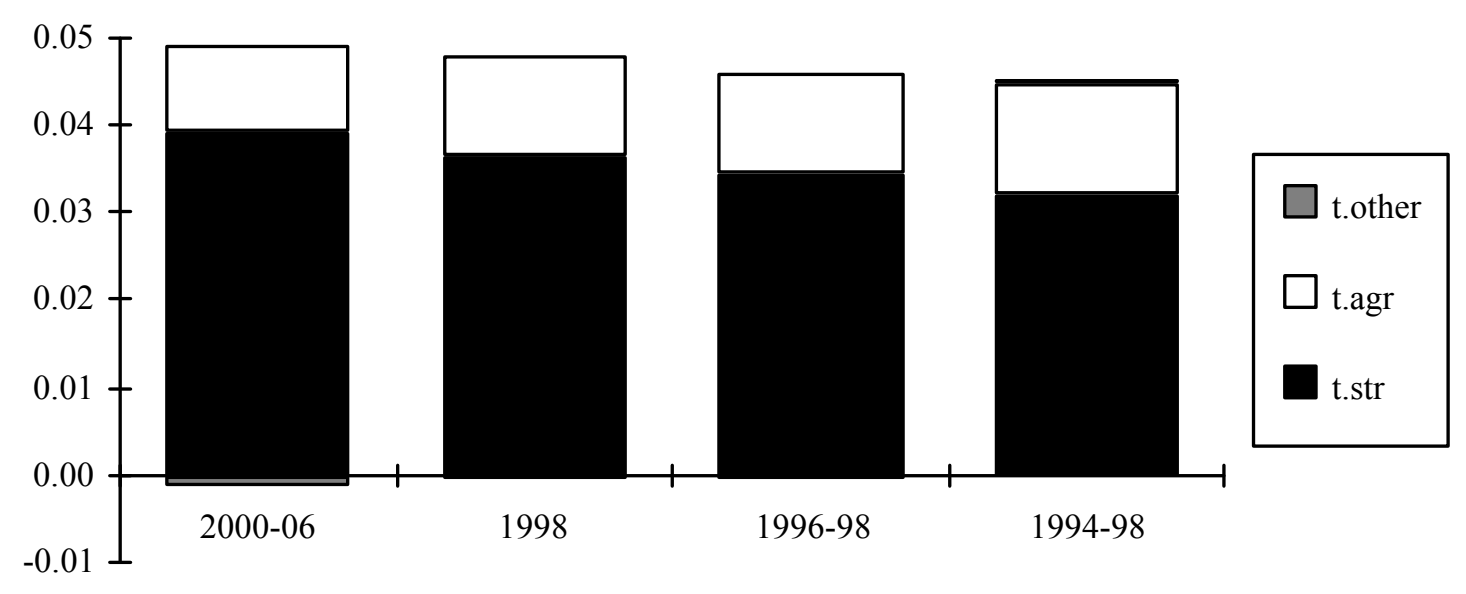

Figure 23: Dispersion of expenditure-side adjusted net balances Berlin agreement vs. three alternative benchmarks

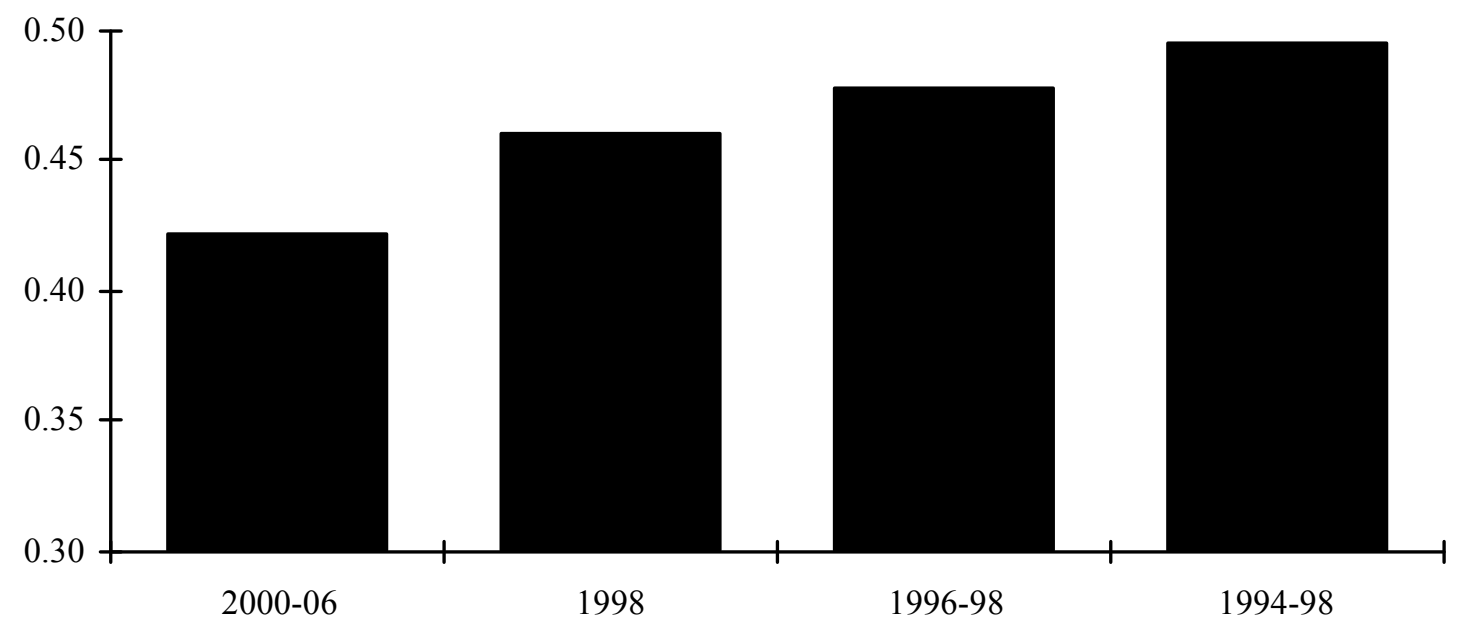


Figures 22-24 summarize the results of the exercise. We find that, in spite of the decline in the relative weight of structural programmes, the Berlin budget agreement represents a noticeable (but far from dramatic) improvement over any of our benchmarks in terms of both the degree of redistribution and the horizontal equity of the expenditure allocation. Relative to the 1994-98 benchmark, the degree of redistribution of the (expenditure side of the) new framework increases by almost $7 \%$ (from 0.0451 to 0.0482). This reflects an increase in the concentration of structural aid in poorer countries (see Figure 22) that raises the redistribution coefficient in spite of the expected reduction in the progressivity of agricultural subsidies. In terms of horizontal equity, the same comparison across financial frameworks yields a $10 \%$ reduction in the weighted standard deviation of the regression residuals (see Figure 23). Figure 24, which displays each country's net adjusted balances under the different scenarios, shows that in most cases these decrease over time in absolute value, although progress is uneven and there are a number of exceptions to this rule. The figure also shows, however, that there remain very important disparities in the fiscal treatment of countries with similar income levels.

Figure 24: Expenditure-side adjusted net balances Berlin agreement vs. three alternative benchmarks

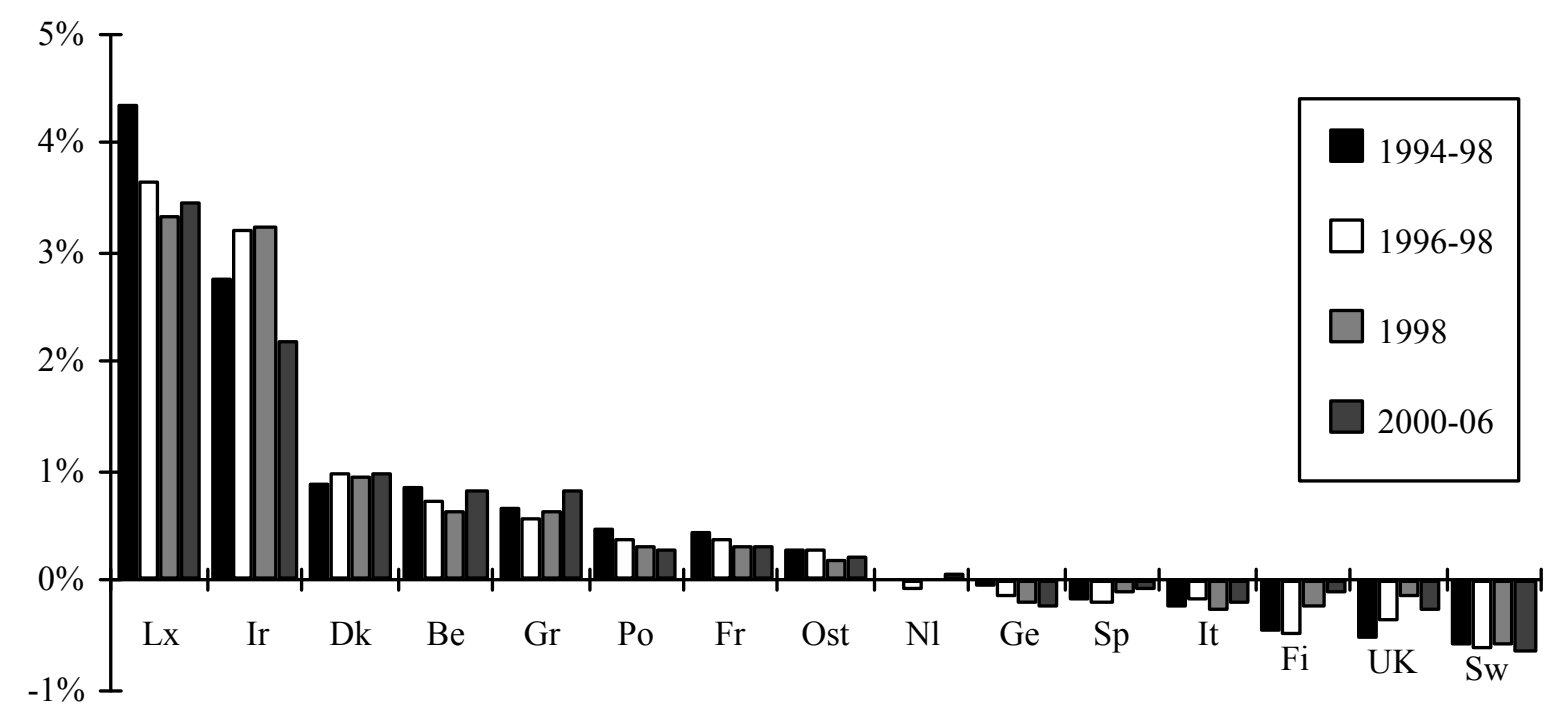

\section{5.- Summary and conclusions}

In the first part of this paper we have developed a simple extension of a standard methodology for the analysis of the redistributive effects of fiscal flows within a federal or quasi-federal system. Using an additive decomposition of net budget balances and a weighted regression specification, we obtain a set of partial redistribution coefficients that add up across expenditure and revenue items to an overall redistribution parameter, and estimates of residual or excess balances after correcting for income per capita that add up in the natural way across programmes for a given country and across countries for a 
given programme. Applying this methodology to EU budget data, we have analyzed its redistributive effects over the period 1986-1998. We find that the redistributive impact of fiscal flows across Union members has been considerable, particularly given the small size of the budget, that it has tended to increase over time, and that it is mostly due to the effect of structural programmes. We also find significant differences in net contributions across countries with similar prosperity levels. In this sense, the current concern about the unfairness of the distribution of net burdens does seem to be justified, although our analysis suggests that the problem has at least as much to do with the inequitable allocation of net contributions across rich countries than with the level of fiscal transfers to poorer member states.

The redistribution equations we have estimated can also be interpreted as a one-parameter family of allocation rules describing how budgetary balances should be set as a function of relative income levels. We have argued for the explicit use of such a rule as a framework for EU budget decisions and for the adoption of a multi-stage budget-setting procedure consistent with it: The Commission and the member states would first agree on the overall expenditure volume, the mechanisms for its financing and the desirable redistribution coefficient. National budgetary balances would then be set on the basis of per capita income prior to the negotiation of specific expenditure programmes. Any discrepancies between the outcome of this last stage and the desired net balance would be eliminated by a compensation mechanism that could take the form of a rebate or surcharge on GNP contributions or supplementary structural allowances. In practice, we would advocate that this procedure be applied in an incremental fashion, taking as given the allocation rule implicit in the status quo and gradually eliminating "excess" balances or adjusting the redistribution coefficient as required by an evolving consensus.

In our opinion, this approach would have several important advantages over current practices. Perhaps the most important ones are that it would provide a transparent way of implementing the principle of cohesion and that it would reduce the scope for real or perceived inequities in the allocation of budget resources by forcing member states to negotiate over a single, easily interpretable, parameter rather than about a host of specific items that may add up to apparently arbitrary allocations. In addition, setting net balances in advance of expenditure programmes will in effect force national governments to bear the marginal cost of Community expenditures, thereby increasing the incentives for a more efficient allocation of resources.

In the last part of the paper, we have examined the implications of our proposed allocation rule, taking as given the redistribution coefficient implicit in the 1998 data, and explored the likely impact of the expenditure side of the current financial perspectives on the level of redistribution across member states and on the horizontal equity properties of the EU budget allocation. We find that, in spite of the planned reduction in the weight of structural programmes, the new budget agreement will represent a small improvement in both the horizontal equity of the system and its degree of redistribution. The margin for further improvement remains, however, quite substantial. 


\section{Appendix}

\section{i.- Normalization of the budget data}

Let $Y_{i}$ and $Q_{i}$ denote country i's income per capita before and after contributions to or transfers from the EU budget. These two variables are related by the following equation

$$
\text { (A.1) } Q_{i}=Y_{i}+N B_{i}=Y_{i}+T_{i}-C_{i}=Y_{i}+\Sigma_{k} T_{k i}-\Sigma_{k} C_{k i}
$$

where $N B_{i}$ is the net EU budget balance of country $\mathrm{i}$, defined as the difference between total transfers from the Union $\left(T_{i}\right)$ and total contributions to it $\left(C_{i}\right)$, both measured in per capita terms. These two variables can be expressed as sums of various per capita expenditure and contribution items $\left(T_{k i}\right.$ and $\left.C_{k i}\right)$.

Let $Y, Q, C$ and $T$ be EU-wide per capita weighted averages of the same variables (i.e. total amounts divided by total EU population). If we assume that the EU budget is balanced and that all expenditure is domestic (which is roughly true as an approximation), then $C=T$ and $Q=Y$. Dividing both sides of (A.1) by $Y(=Q)$, we can express all quantities as proportions of average EU income per capita. Letting lower-case letters denote these new normalized variables, we have

$$
\text { (A.2) } q_{i}=y_{i}+n b_{i}=y_{i}+t_{i}-c_{i}=y_{i}+\Sigma_{k} t_{k i}-\Sigma_{k} c_{k i}
$$

for country $i$ and

$$
\text { (A.3) } q=y+t-c=Y+\Sigma_{k} t_{k}-\Sigma_{k} c_{k}
$$

for the average of the EU. Letting $\tilde{x}_{i}=x_{i}-x$ denote the deviation of each variable $x$ from its EU weighted average and subtracting (A.3) from (A.2) we obtain

$$
\text { (A.4) } \tilde{q}_{i}=\tilde{y}_{i}+\tilde{t}_{i}-\tilde{c}_{i}=\tilde{y}_{i}+\tilde{n b}_{i}=\tilde{y}_{i}+\Sigma_{k} \tilde{t}_{k i}-\Sigma_{k} \tilde{c}_{k i}
$$

That is, the relative disposable income of country i (in \% deviations from average disposable income) is the sum of the country's gross relative income and the algebraic sum of its contributions to and transfers from the EU budget, measured as proportions of average EU income and expressed as deviations from their average values in the sample. Equation (1) in the text is derived from equation (A.4) after subtracting $\tilde{y}_{i}$ from both sides in order to leave $\tilde{n b}_{i}$ on the left-hand side. Notice that the notation changes slightly, as the tildes are omitted in the text. 
ii.- Estimation procedure and additivity properties of the redistribution coefficients and adjusted balances

As noted in the text, we estimate equations of the form

$$
\text { (A.5) } n b_{i}=-\rho_{b} y_{i}+\varepsilon_{b i} \quad\left(\text { A.6) } t _ { k i } = - \rho _ { t k } y _ { i } + \varepsilon _ { t k i } \quad \text { and } \quad \left(\text { A.7) } c_{k i}=\rho_{c k} y_{i}+\varepsilon_{c k i}\right.\right.
$$

using the normalized data and a weighted least squares procedure. Focusing on equation (A.5) for concreteness, we choose $\rho b$ so as to minimize the weighted sum of the squared residuals,

$$
\text { (A.8) } R=\Sigma_{i} w_{i} \varepsilon_{b i}{ }^{2}=\Sigma_{i} w_{i}\left(n b_{i}+\rho_{b} y_{i}\right)^{2}
$$

where $w_{i}$ is the share of country $i$ in the total population of the EU. Setting the derivative of $R$ with respect to $\rho_{b}$ equal to zero and solving for this parameter we obtain the following WLS estimator:

$$
\text { (A.9) } \rho b=-\sum_{i} w_{i} n b_{i} y_{i} / \sum_{i} w_{i} y_{i}{ }^{2}
$$

By a similar argument, the partial redistribution coefficients for total transfers and contributions are given by

$$
\text { (A.10) } \rho_{t}=-\Sigma_{i} w_{i} t_{i} y_{i} / \Sigma_{i} w_{i} y_{i}^{2} \text { and (A.11) } \rho_{c}=-\Sigma_{i} w_{i} c_{i} y_{i} / \Sigma_{i} w_{i} y_{i}{ }^{2}
$$

respectively. Hence, we have

$$
\text { (A.12) } \rho_{t}+\rho_{C}=-\left(\sum_{i} w_{i} t_{i} y_{i}-\Sigma_{i} w_{i} c_{i} y_{i}\right) / \Sigma_{i} w_{i} y_{i}^{2}=-\Sigma_{i} w_{i} n b_{i} y_{i} / \Sigma_{i} w_{i} y_{i}{ }^{2 .}=\rho b
$$

so the partial redistribution coefficients add up to the total redistribution parameter. Using (A.12), and (A.5) - (A.7), moreover, we have

$$
\text { (A.13) } \begin{aligned}
n b_{i}=t_{i}-c_{i} & =-\rho_{t} y_{i}+\varepsilon_{t i}-\rho_{c} y_{i}-\varepsilon_{C i}=-\left(\rho_{t}+\rho_{C}\right) y_{i}+\left(\varepsilon_{t i}-\varepsilon_{C i}\right) \\
& =-\rho_{b} y_{i}+\left(\varepsilon_{t i}-\varepsilon_{C i}\right)
\end{aligned}
$$

from where it follows that $\varepsilon_{b i}=\varepsilon_{t i}-\varepsilon_{c i}$, that is, that the adjusted partial balances add up across programs to the net budget balance for each country.

Finally, we show that the weighted sum of the residuals is equal to zero in any given equation. Working with (A.5) and reintroducing the tildes as needed to emphasize that we are working with normalized variables in deviations from EU-wide averages, we have:

$$
\text { (A.14) } \sum_{i} w_{i} \varepsilon_{b i}=\sum_{i} w_{i}\left(\tilde{n b}_{i}+\rho_{b} \tilde{y}_{i}\right)=\sum_{i} w_{i} \tilde{n b}_{i}+\rho_{b} \sum_{i} w_{i} \tilde{y}_{i}
$$




$$
=\Sigma_{i} w_{i}\left(n b_{i}-n b\right)+\rho_{b} \Sigma_{i} w_{i}\left(y_{i}-y\right)=0+\rho_{b} 0=0
$$

where the variables without a subscript denote (weighted) EU averages. Hence, $y=\sum_{i} w_{i} y_{i}, n b=\sum_{i} w_{i} n b_{i}$, and the desired equality follows. Notice that the result follows from the normalization of the data and holds independently of how $\rho_{b}$ is estimated.

\section{References}

Bayoumi, T. and P. Masson (1995). "Fiscal flows in the United States and Canada: Lessons for monetary union in Europe." European Economic Review 39, pp. 252-74.

de la Fuente, A. (1997). "Desigualdad regional en España: la incidencia de la imposición directa sobre las familias y el sistema de protección social." Documento de Trabajo PT 59.97, Instituto de Análisis Económico (CSIC), Barcelona.

de la Fuente, A. and R. Doménech (1999). "The redistributive effects of the EU budget: an analysis and some reflections on the Agenda 2000 negotiations." CEPR Discussion Paper No. 2113.

Doménech, R., A. Maudes and J. Varela (2000). "Fiscal flows in Europe: the redistributive effects of the EU budget." Mimeo, Ministry of Economics and Finance, Madrid. (Available at: http://iei.uv.es/ rdomenec/EUbudget.htm).

European Union (1999). Presidency conclusions. Berlin European Council.

European Commission (1997). Agenda 2000. Volume I, Communication: For a stronger and wider Union. Strasbourg.

Martin, C. (2000). The Spanish economy in the new Europe. Macmillan Press.

Sala-i-Martin, X. and J. Sachs (1992). "Fiscal federalism and optimum currency areas: Evidence for Europe from the United States," in M. Canzoneri, V. Grilli and P. Masson, editors, Establishing a central bank: Issues in Europe and lessons from the U.S. Cambridge University Press, Cambridge, pp. 195-219.

The Economist (1999). "European farming: Against the grain." Feb. 20th 1999, pp. 30-1.

von Hagen, J. (1992). "Fiscal arrangements in a monetary union: Evidence from the U.S." in D. Fair and Ch. Boissieux, editors, Fiscal policy, taxes and the financial system in an increasingly integrated Europe. Kluwer, Deventer. 
Figure 11: Adjusted net relative balances
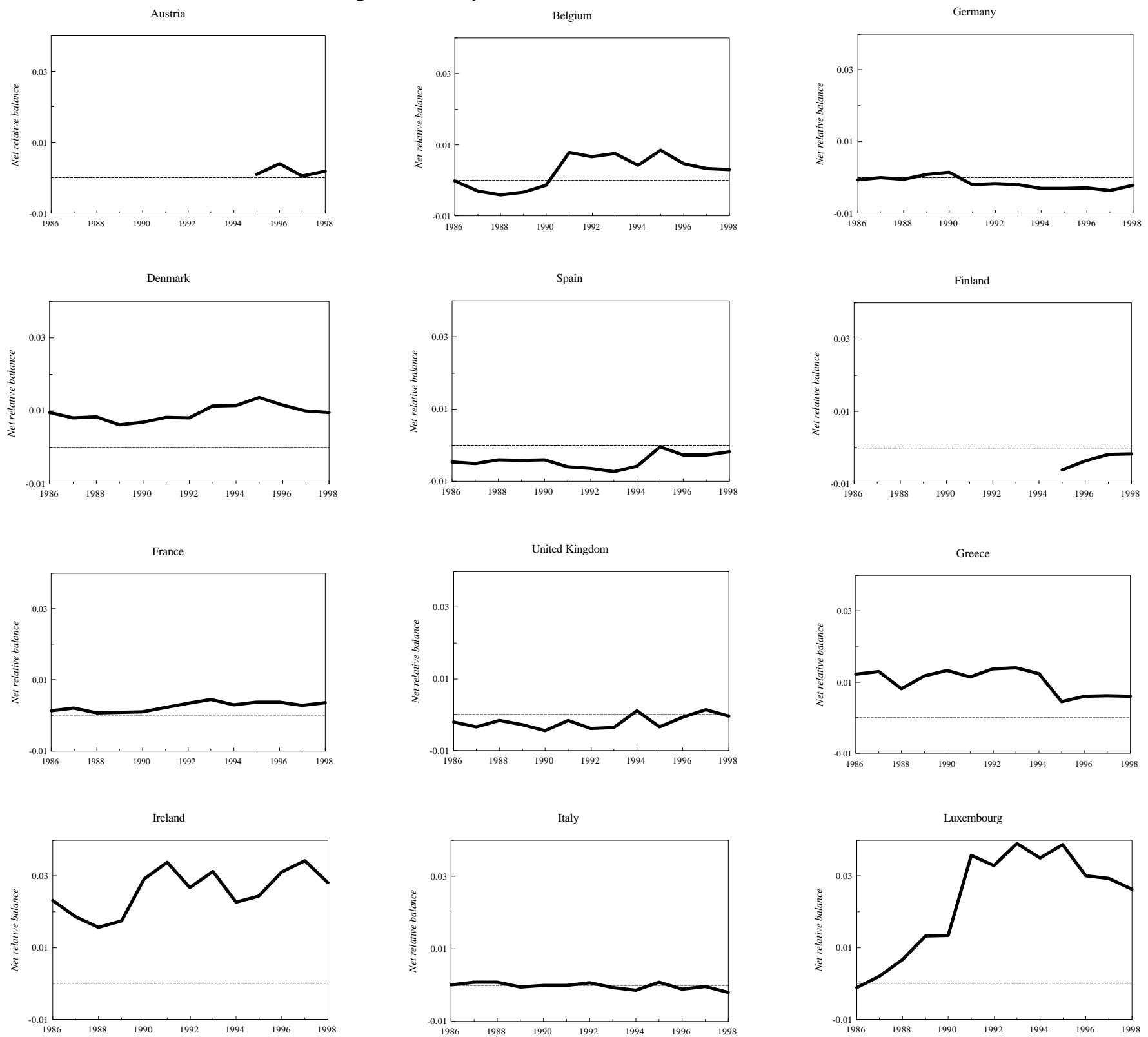

Italy
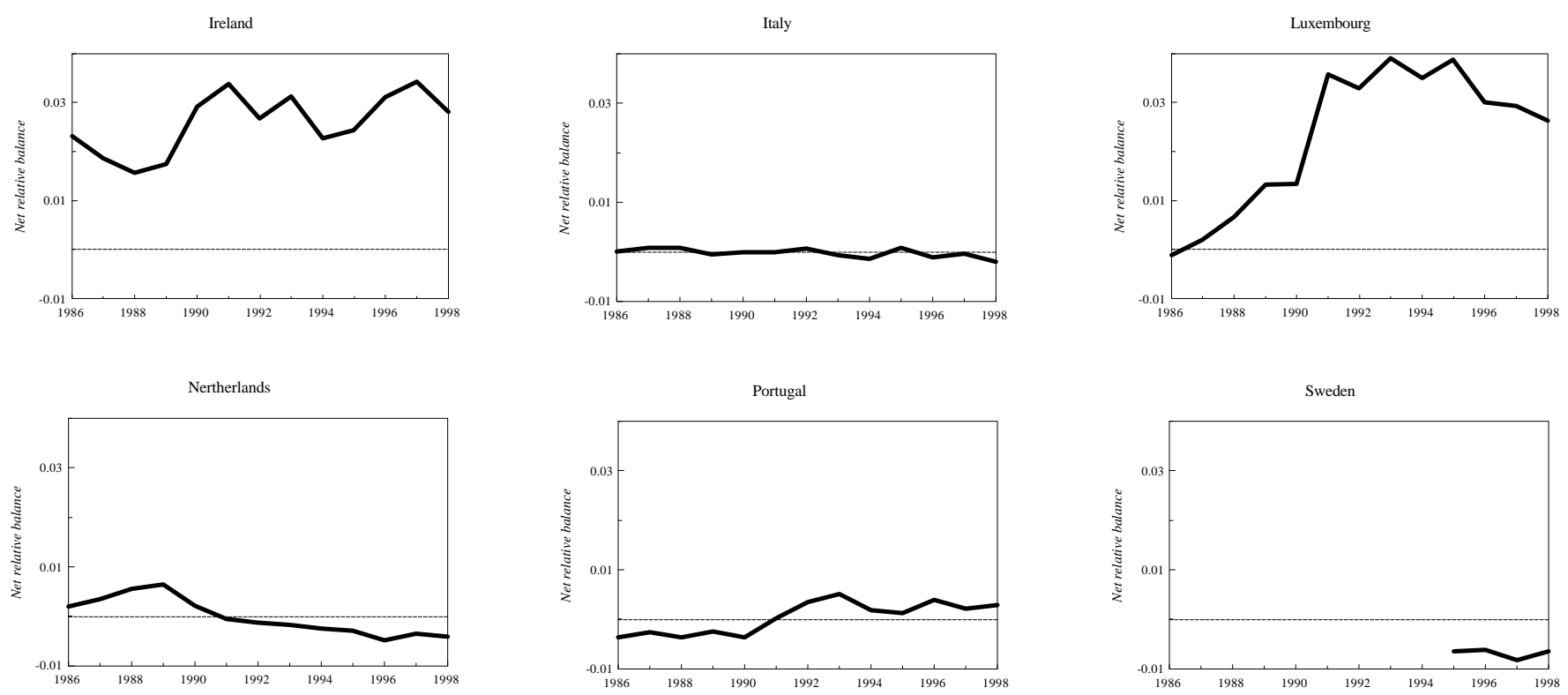
Austria

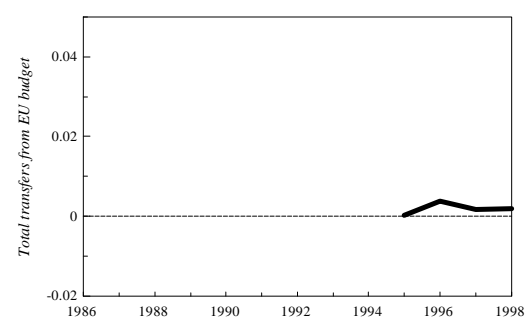

Denmark

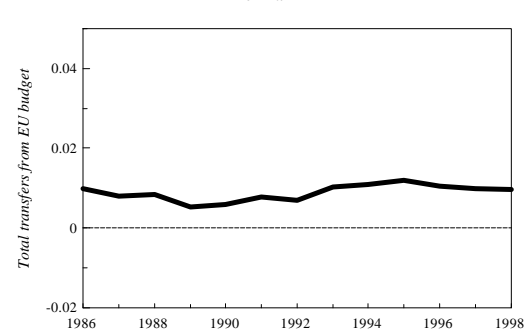

France

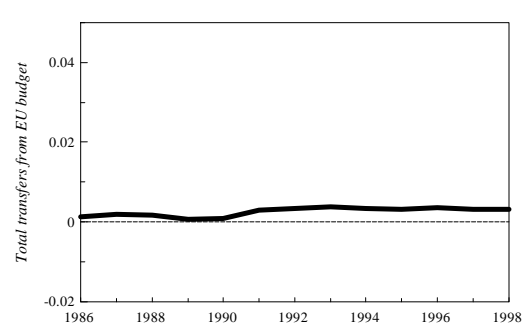

Ireland

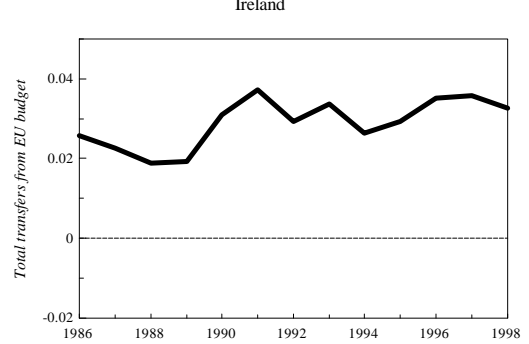

Netherlands

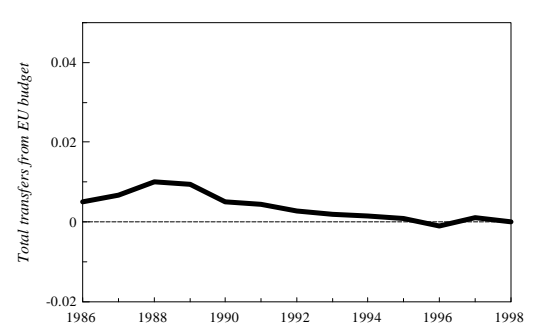

Figure 12: Adjusted total transfers
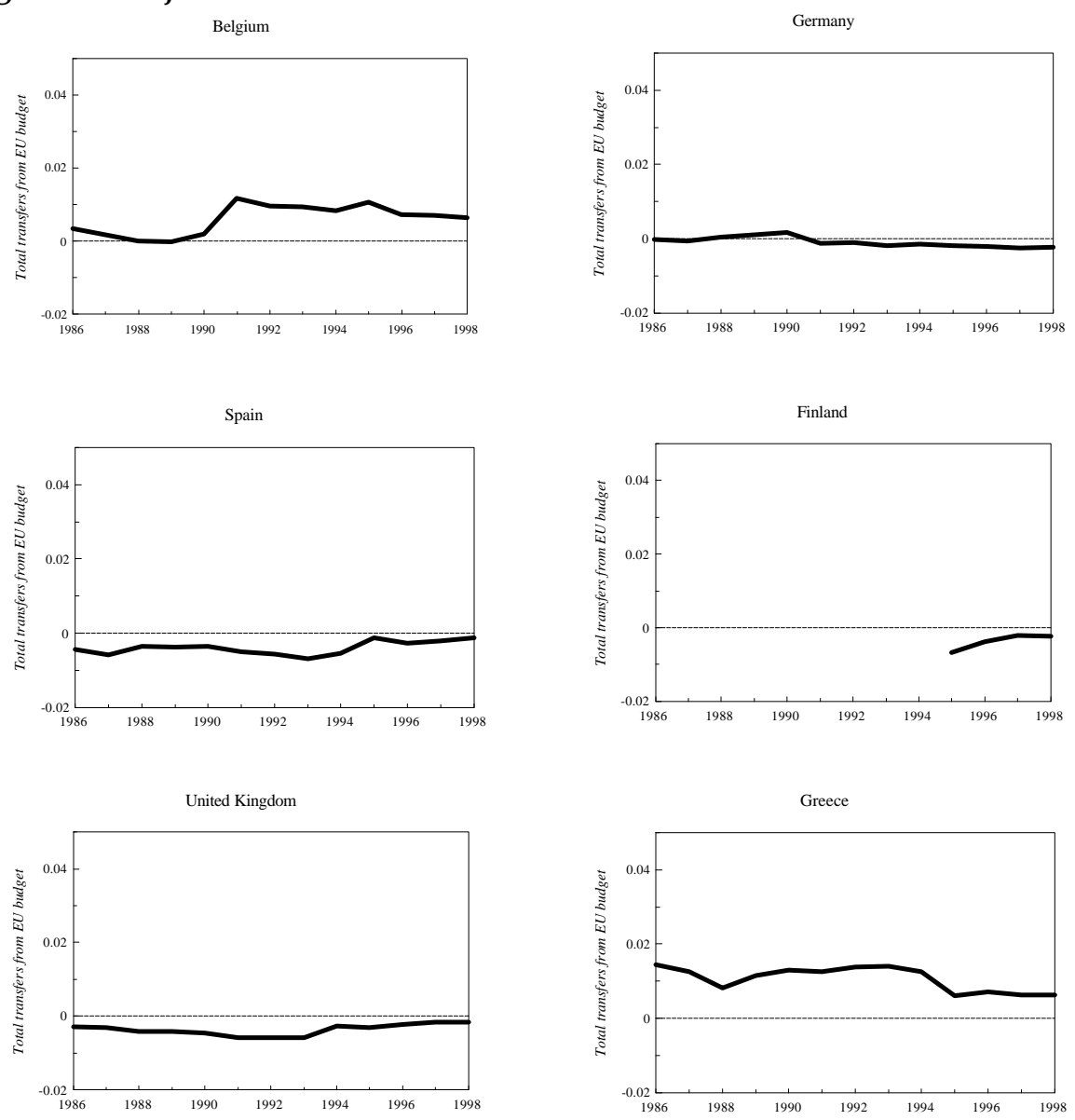

Italy
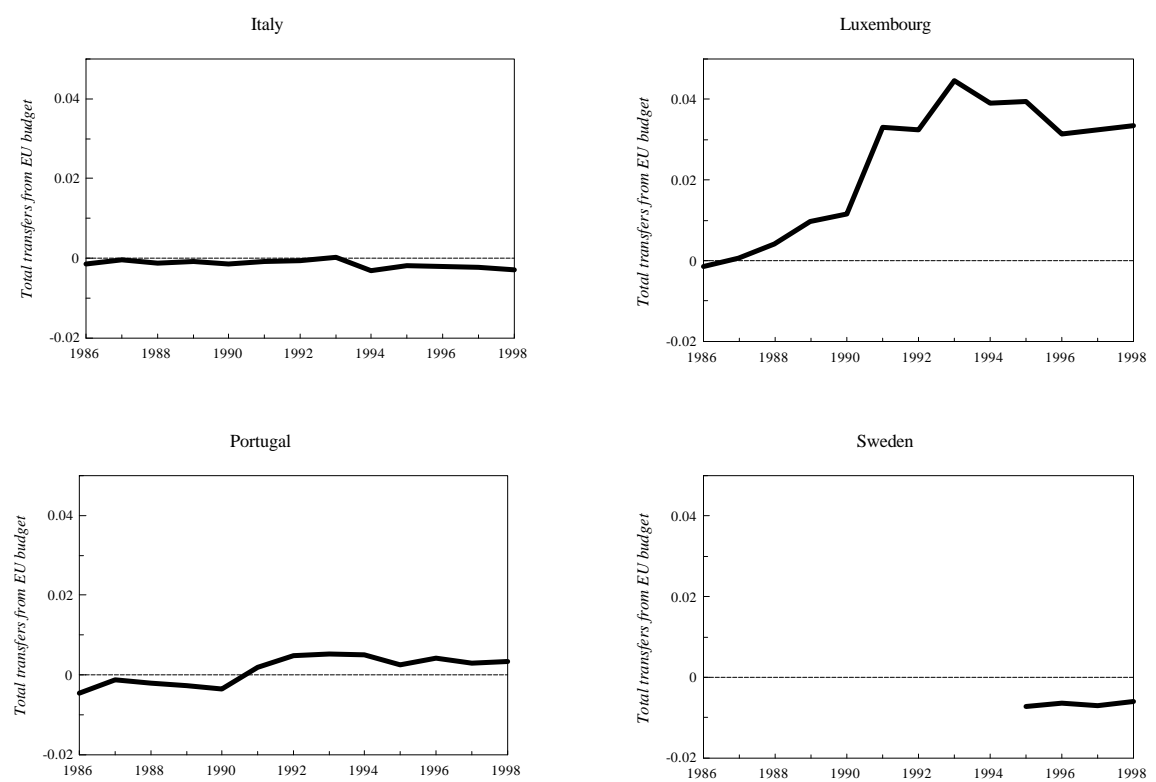
Figure 13: Adjusted total contributions
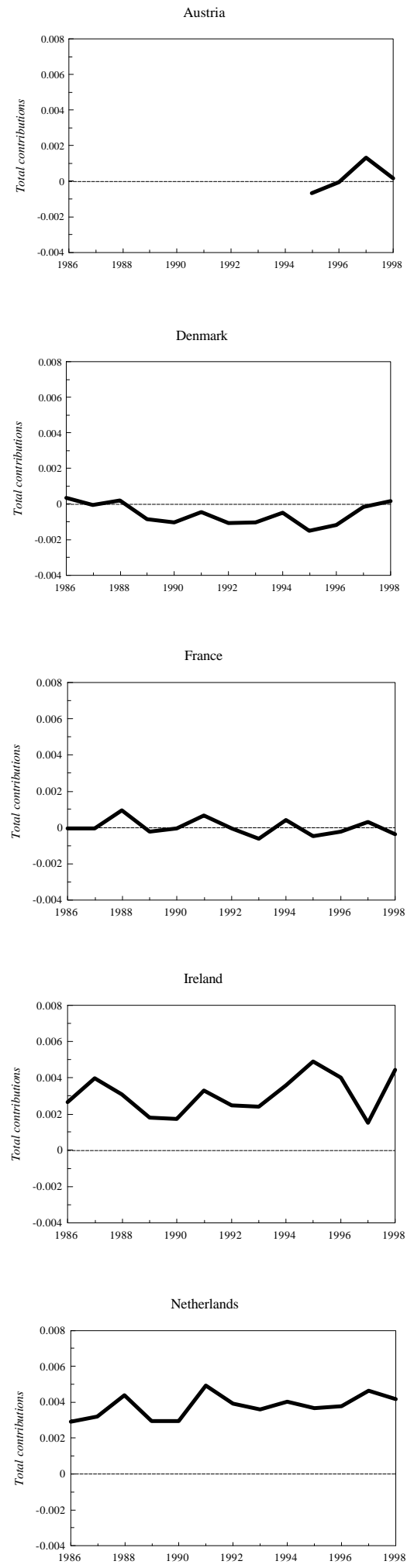
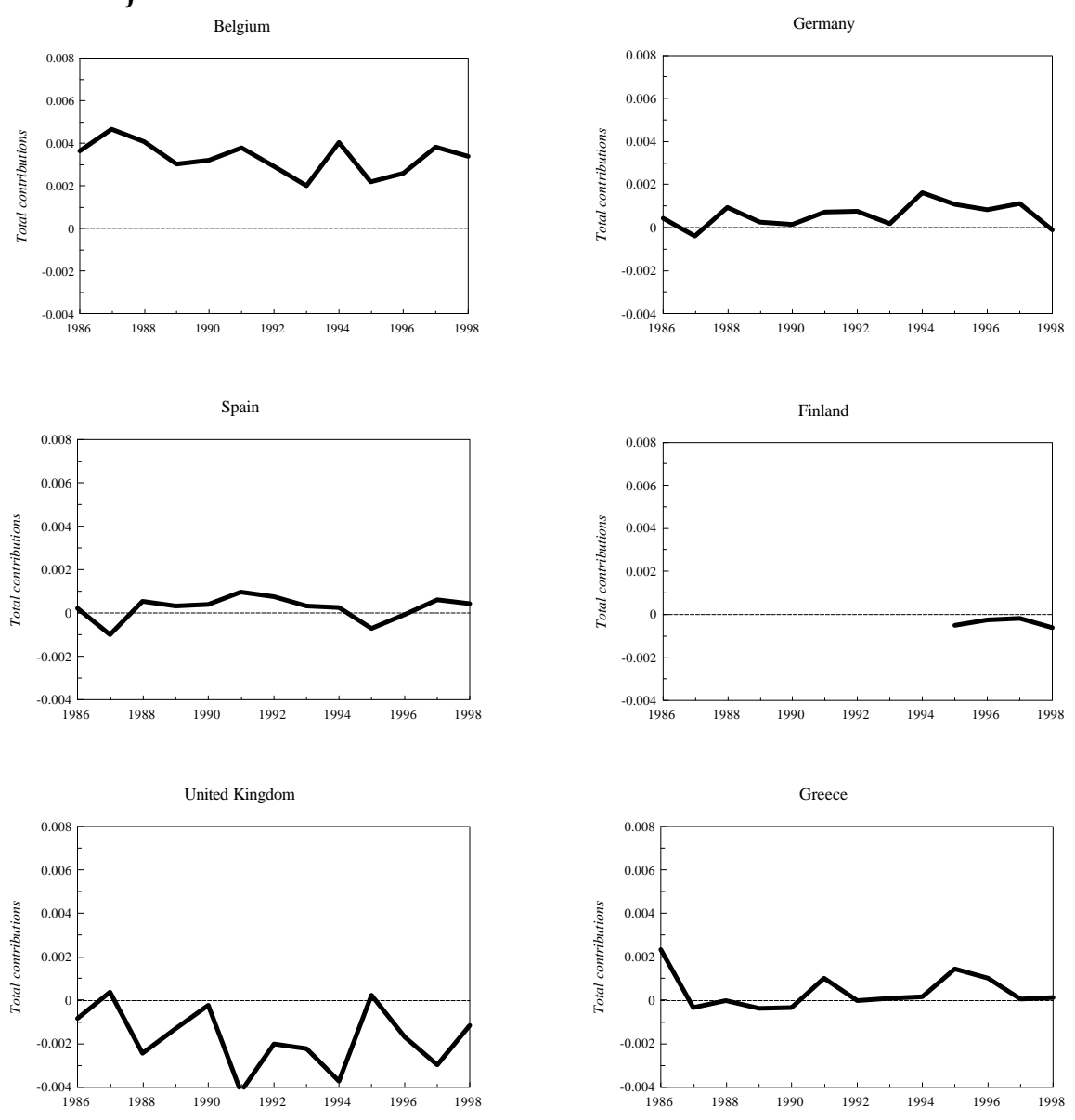

Italy
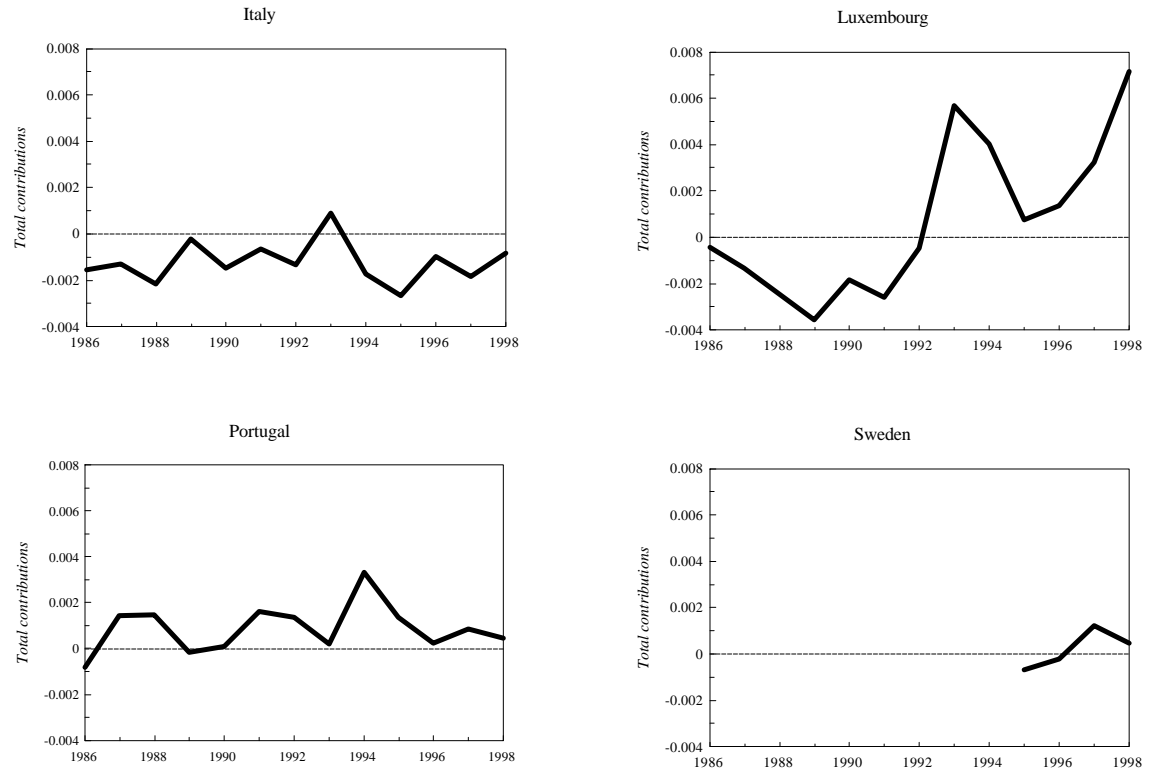


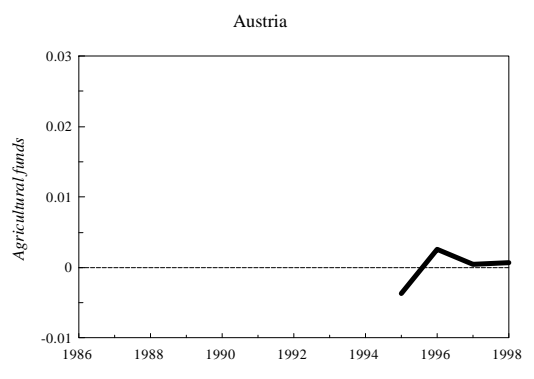

Figure 14: Adjusted agricultural funds
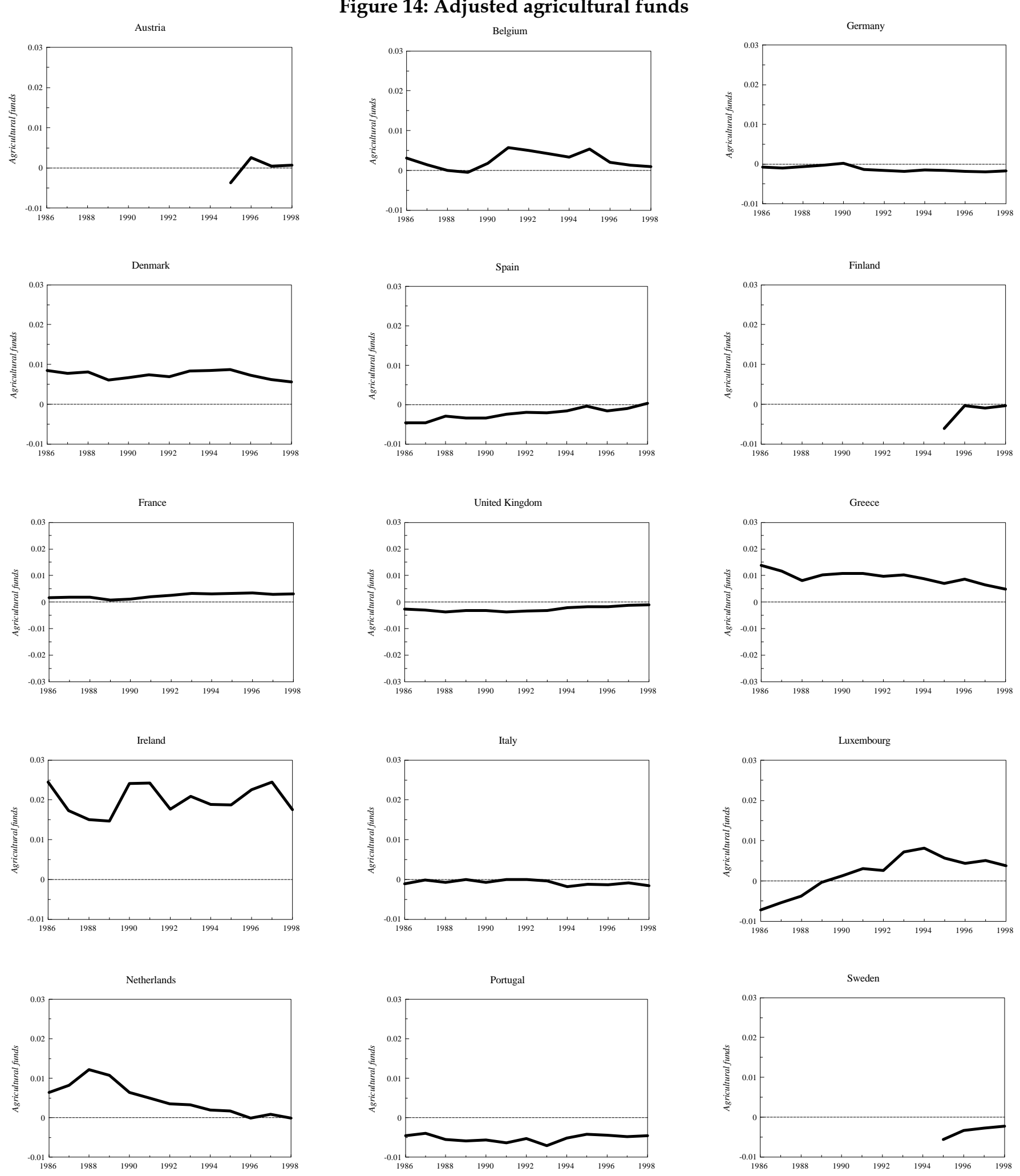


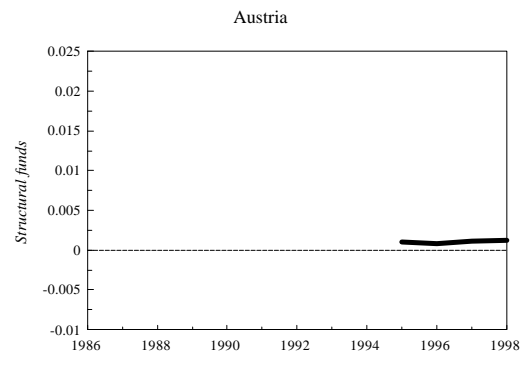

Figure 15: Adjusted structural funds
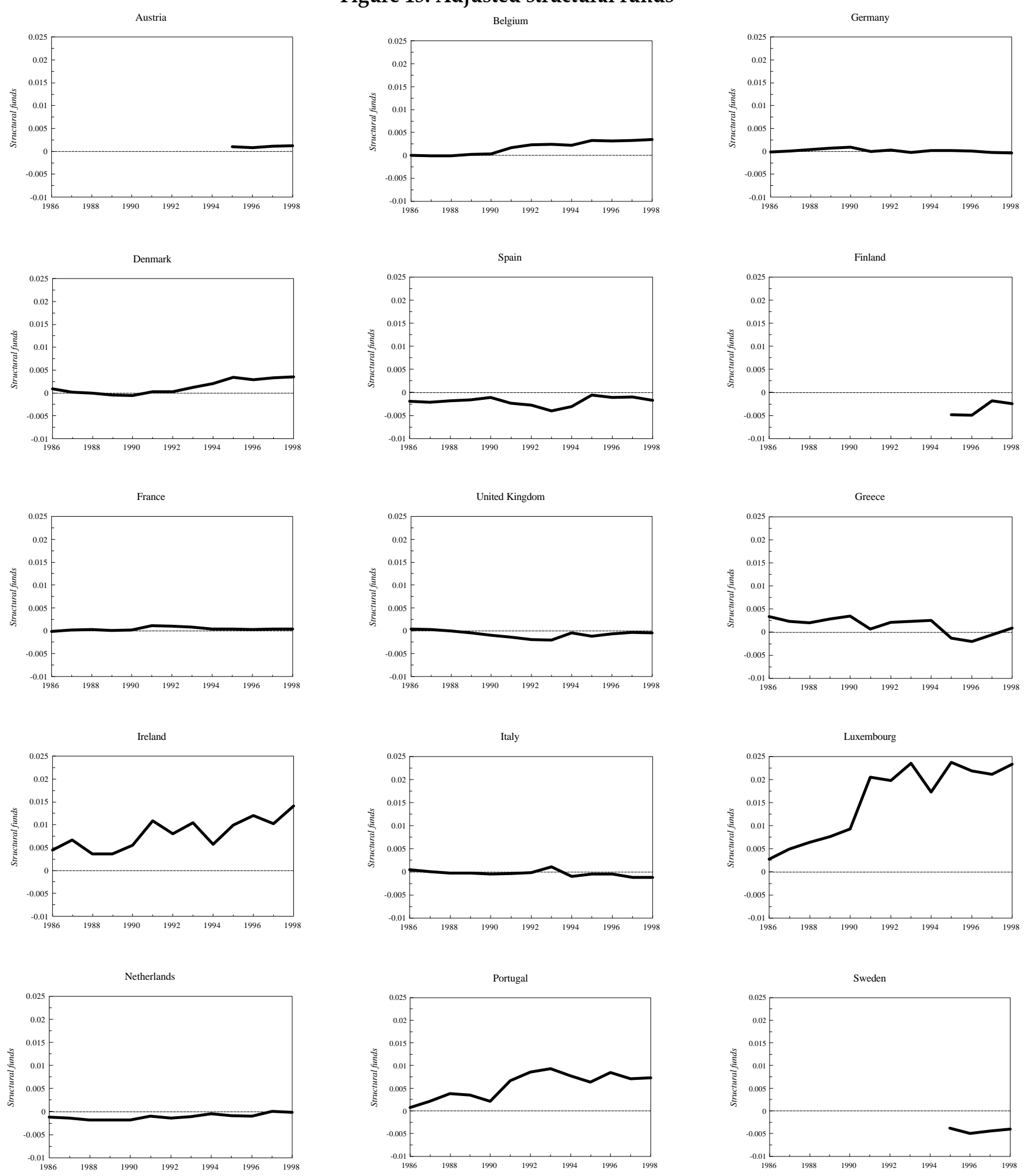
Figure 16: Adjusted values of other funds
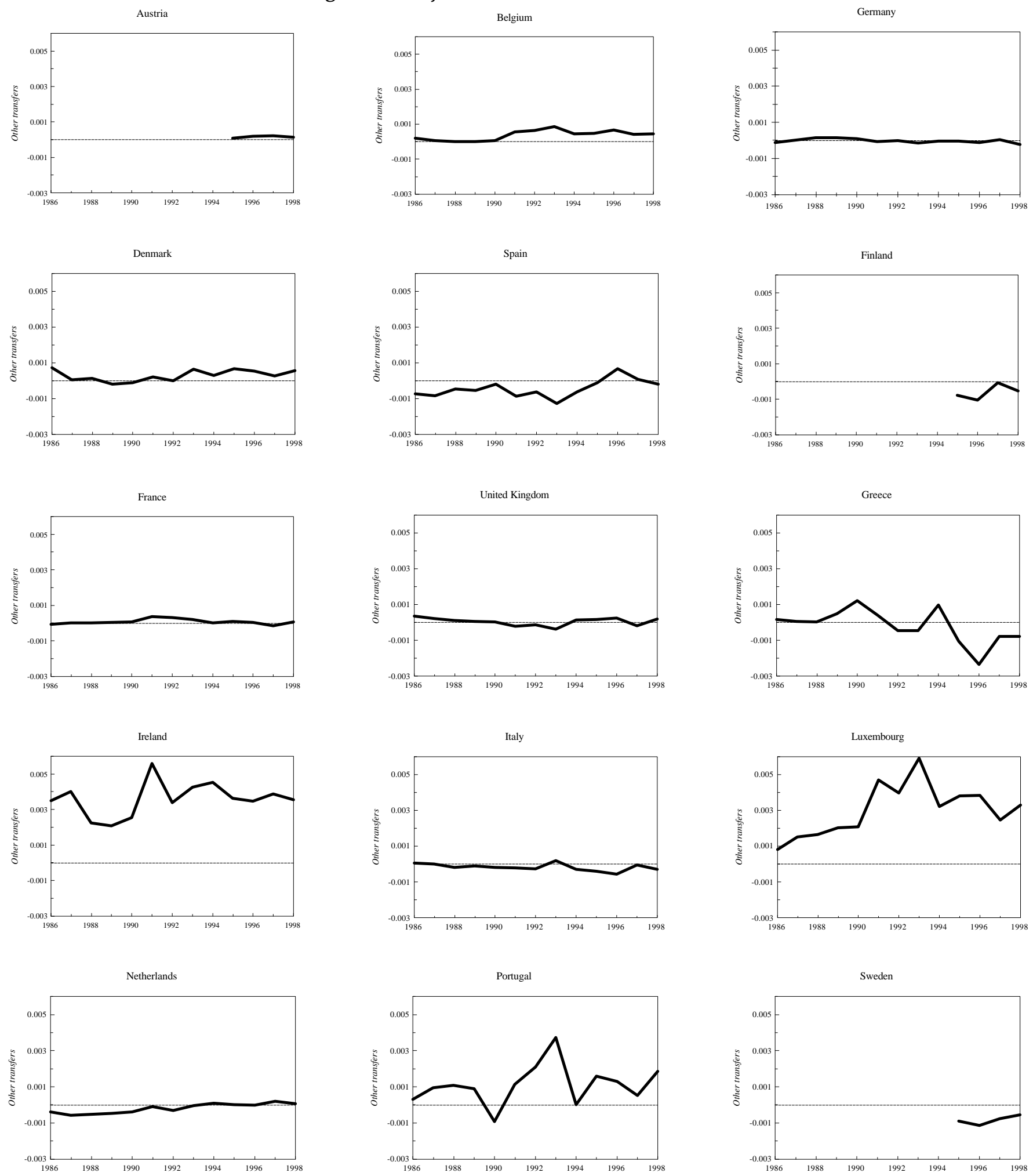
Figure 17: Adjusted traditional contributions
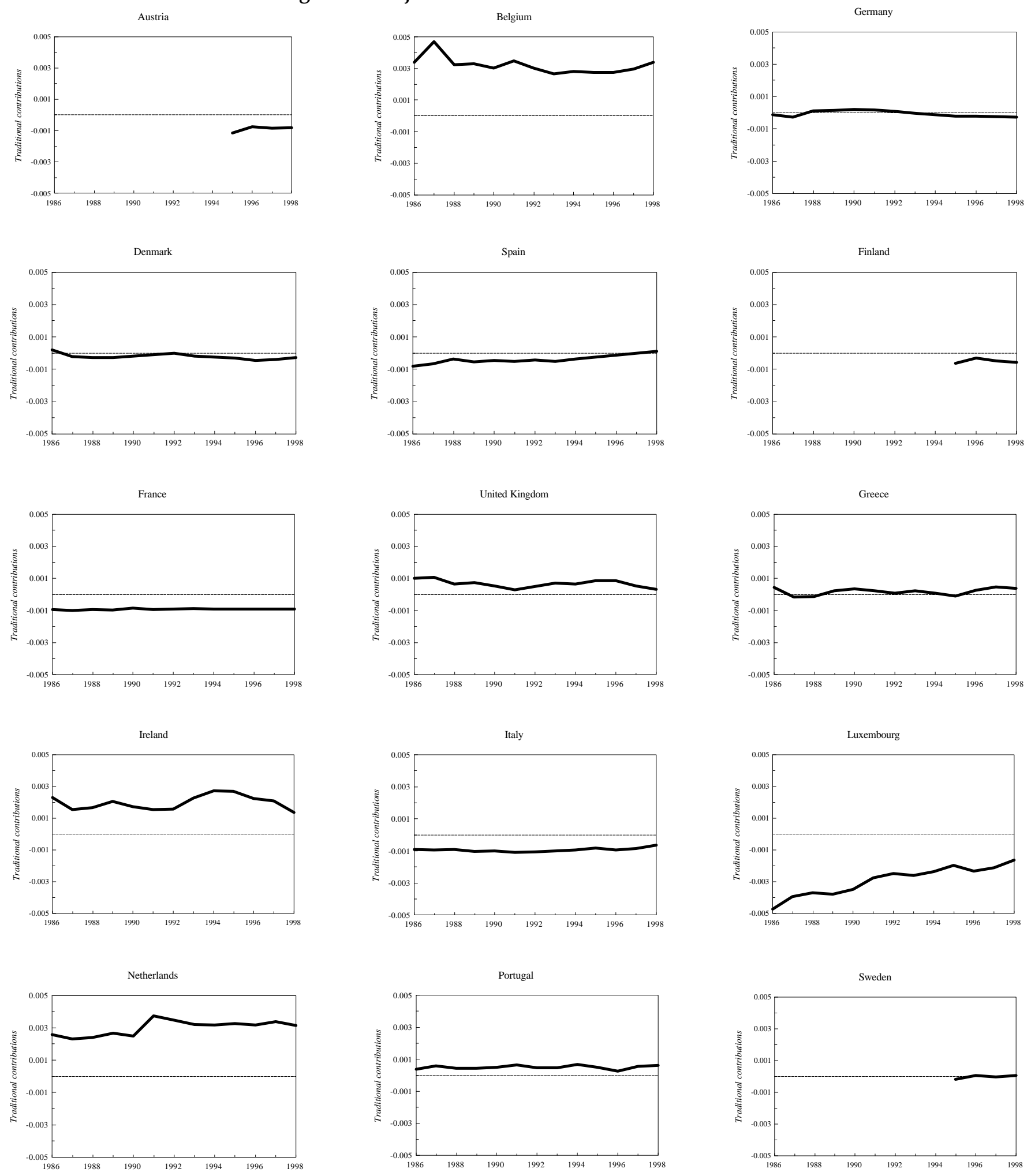


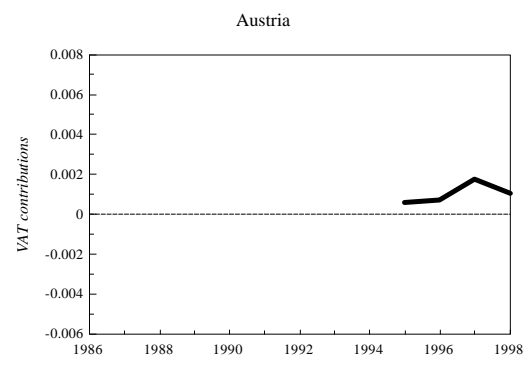

Figure 18: Adjusted VAT contributions
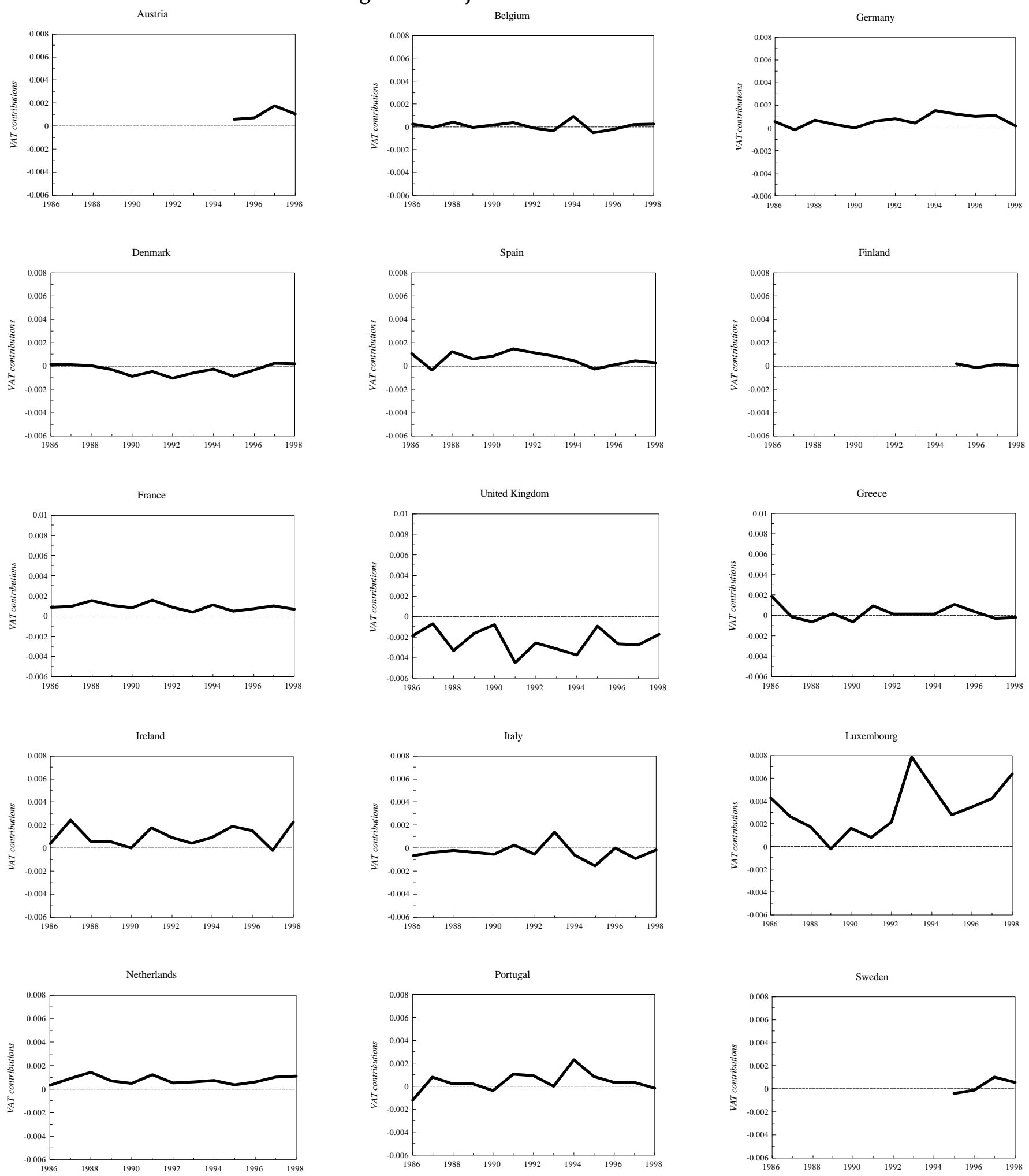


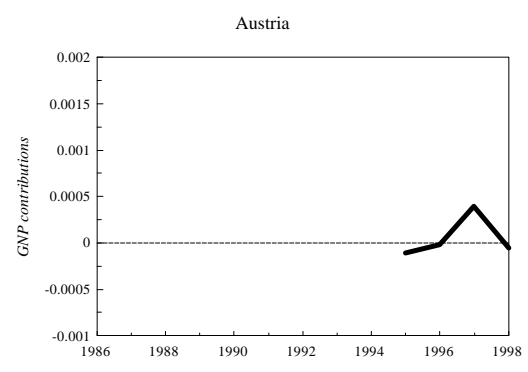

Figure 19: Adjusted GNP contributions
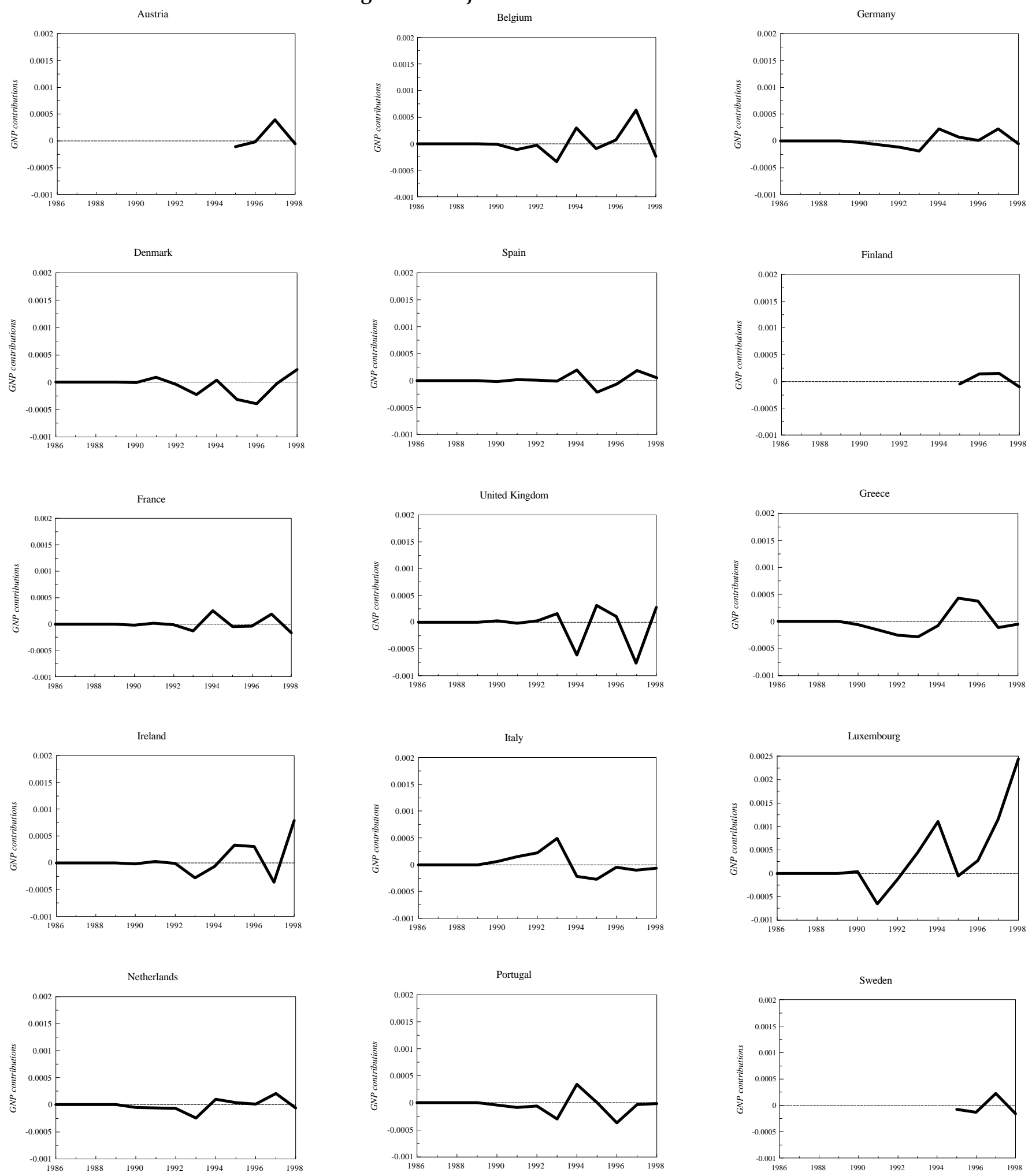